\title{
Vibrational Analysis of Peptides, Polypeptides, and Proteins. XXIV. Conformation of Poly( $\alpha$-Aminoisobutyric Acid)
}

\author{
ANIL M. DWIVEDI* and S. KRIMM, Biophysics Research Division, \\ University of Michigan, Ann Arbor, Michigan 48109; and B. R. \\ MALCOLM, Department of Molecular Biology, University of \\ Edinburgh, Edinburgh EH9 3JR, United Kingdom
}

\section{Synopsis}

Raman and polarized ir spectra have been obtained on built-up monomolecular films of poly( $\alpha$-aminoisobutyric acid), and analyzed in the context of normal mode calculations on $3_{10}, \alpha-$, and $\alpha^{\prime}$-helix conformations of this molecule. The average discrepancy between observed and calculated frequencies is significantly smaller for the $3_{10}$-helix than for the other structures. This, together with the more satisfactory explanation of several special features of the spectra, indicates that this polypeptide adopts a $3_{10}$-helix conformation in such thin films.

\section{INTRODUCTION}

Peptide units containing $\alpha$-aminoisobutyric acid (AIB) residues exert significant constraints on the conformational freedom of the polypeptide backbone. ${ }^{1-6}$ This constraint arises from the steric interactions between the two methyl groups attached to the $\mathrm{C}^{\alpha}$ atom, resulting in restrictions on the dihedral angles of the backbone to values very close to those of right- or left-handed $3_{10}$-or $\alpha$-helices.

Burgess and Leach ${ }^{1}$ have suggested an obligatory $\alpha$-helical structure for poly( $\alpha$-aminoisobutyric acid) (PAIB). Malcolm, ${ }^{7,8}$ on the basis of ir and electron-diffraction studies of oriented films of PAIB, has reported a $3_{10}$-helical structure. Also, experimental work on small peptides containing AIB residues has demonstrated that the conformation of the backbone is always a right- or left-handed $33_{10}$-helix. ${ }^{9-15}$ Using classical potential energy functions and energy minimization, Venkataram Prasad and Sasisekharan ${ }^{2}$ have worked out the relative stabilities of $\alpha$ - and $33_{10}$-helical structures for PAIB. Their analysis indicates the necessity for nonplanar distortion of the peptide units as observed in the crystal structures of peptides with AIB residues, ${ }^{9-15}$ and they propose a helical structure with $n=4$ and $h=1.5 \AA$ (named $\alpha^{\prime}$ ) as energetically more favorable than the standard $3_{10}$-helix. Recently,

* Present address: Analytical Research, Johnson Wax, Racine, WI 53403. 
Patterson et al., ${ }^{3}$ in their conformational analysis of oligomers of AIB, have shown that the conformation is very sensitive to the covalent geometry of the residue, particularly the bond angles between the substituents on the $\mathrm{C}^{a}$ atom. Symmetrical tetrahedral geometry around $\mathrm{C}^{\alpha}$ favors the $\alpha$-helical conformation, whereas the asymmetric geometry observed in most of the crystals ${ }^{9-15}$ gives the $3_{10}$-conformation as the favored structure.

Such variations among the various theoretically proposed structures prompted us to undertake a vibrational spectroscopic analysis of the structure of PAIB. With our success in deriving maximally transferrable vibrational force fields for polypeptides, ${ }^{16-22}$ we are now in a position to exploit the full potential of vibrational spectroscopy in determining structure in polypeptides and proteins. ${ }^{23}$ The applicability of such techniques has already been demonstrated by some of the work reported from our laboratory. ${ }^{24-30}$

Except for brief reports by Elliot ${ }^{31}$ and Malcolm, ${ }^{7}$ there has been no attempt to analyze the ir and Raman spectra of PAIB. In this paper we report Raman and polarized ir spectra of multimonomolecular layers of PAIB and N-deuterated PAIB (PAIB-ND). Normal mode analysis was carried out using three structural models, the $\alpha$-helix, ${ }^{32}$ the $3_{10^{-}}$ helix, ${ }^{2}$ and the $\alpha^{\prime}$-helix. ${ }^{2}$ Since the same force field is used for the three calculations, the results distinctly show the influence of conformation on the vibrational frequencies. A comparison between the theoretical prediction and the experimental results clearly indicates that of the three structures, the $3_{10}$-helix gives the best frequency fit. Thus, the vibrational analysis suggests that in such very thin films, PAIB has a $3_{10}$-helical conformation.

\section{MATERIALS AND METHODS}

The polymer employed in this study was a small specimen prepared by W. E. Hanby of Courtaulds Limited and is the same as used previously. ${ }^{7}$ Oriented samples were prepared by first dissolving about 5 $\mathrm{mg}$ polymer in $0.5 \mathrm{~mL}$ dichloroacetic acid, purified by vacuum distillation. The solution was made up to $5 \mathrm{~mL}$ with chloroform (reagent grade, redistilled). Approximately $0.005 \mathrm{~mL}$ of the solution was spread on the surface of twice-distilled water in a Langmuir trough, forming a molecular monolayer that was then collapsed between two barriers moved across the surface. The final separation of the barriers was slightly greater than the width of the specimen plate used to remove the film. The film was removed by drawing the plate, with an up and down motion, across the surface between the barriers. This produced a specimen oriented with the polymer chains aligned parallel to the up and down motion of the plate. The specimen was dried down on the plate and the procedure was repeated until sufficient polymer had been deposited to give good spectra. Plates of barium fluoride or KRS5 
were used for ir spectra and pieces of microscope slide for Raman spectroscopy. $\mathrm{N}$-deuterated specimens were prepared in a similar manner by using O-deuterated dichloroacetic acid, and the monolayers were spread on dilute $\mathrm{HCl}(\mathrm{pH} 3)$ to minimize exchange with hydrogen.

The ir spectra were recorded on a Perkin-Elmer 577 or 598 spectrophotometer. The peak positions are accurate to $\pm 2 \mathrm{~cm}^{-1}$. For polarized ir spectra a wire-grid polarizer with the specimen set at $45^{\circ}$ to the slit of the spectrometer was used. Raman spectra were recorded on a Spex 1403 spectrometer at a resolution of $\sim 2 \mathrm{~cm}^{-1}$. The power on the samples, at the 5145 - $\AA$ line of an Ar ion laser, was about 130 and $100 \mathrm{~mW}$ for undeuterated and deuterated specimens, respectively.

\section{NORMAL MODE CALCULATION}

\section{Structure, Symmetry, and Selection Rules}

For the normal mode calculations we used an isolated helical chain structure, since interchain interactions are expected to be very weak. The structural parameters (bond lengths, bond angles, and hydrogen bonds) and the dihedral angles $\left(\phi=-57.37^{\circ}\right.$ and $\left.\psi=-47.49^{\circ}\right)$ for the $\alpha$-helical structure were the same as those derived by Arnott and Dover $^{32}$ from an x-ray diffraction refinement procedure. For the $3_{10^{-}}$ helix ( $n=2.99, h=2.01 \AA, \phi=-45^{\circ}$, and $\psi=-30^{\circ}$ ) and the $\alpha^{\prime}$ helix $\left(n=4.00, h=1.48 \AA, \phi=-55^{\circ}\right.$, and $\left.\psi=-60^{\circ}\right)$, the structural parameters reported by Venkataram Prasad and Sasisekharan ${ }^{2}$ were used. (We have chosen the structure for the $3_{10}$-helix that is closest to the standard one, namely, with three residues per turn and an axial repeat of $6 \AA .^{33}$ Although it appears not to be the lowest energy structure, the dihedral angles of the latter, viz., $\phi=-50^{\circ}, \psi=-30^{\circ}{ }^{2}$ are close enough that the vibrational frequencies are not expected to be significantly different.) The hydrogen-bonding pattern is different in the three structures, the $3_{10}$-helix being of the $i+3 \rightarrow i$ type, while the $\alpha$ - and $\alpha^{\prime}$-helices are of the $i+4 \rightarrow i$ type. The hydrogen-bond strengths are in the order $3_{10}>\alpha>\alpha^{\prime}$ (hydrogen-bond parameters for all the three helices are listed in Table I).

Except for $\mathrm{H}^{\alpha}$ being replaced by a $\mathrm{CH}_{3}$ group [the $\mathrm{CH}_{3}(2)$ group], the chemical residue in PAIB is the same as in poly(L-alanine), and thus,

TABLE I

Hydrogen-Bond Parameters for $3_{10^{-}}, \alpha_{-}$, and $\alpha^{\prime}$-Helices

\begin{tabular}{llccc}
\hline & & $3_{10}$-Helix & $\alpha$-Helix & $\alpha^{\prime}$-Helix \\
\hline$r($ H . . O $)$ & $(\AA)$ & 1.828 & 1.882 & 2.084 \\
$r(\mathrm{~N} \ldots \mathrm{O})$ & $(\AA)$ & 2.825 & 2.857 & 3.065 \\
$<(\mathrm{NHO})$ & $(\mathrm{deg})$ & 175.11 & 164.19 & 166.30 \\
$<(\mathrm{HNO})$ & $(\mathrm{deg})$ & 3.15 & 10.34 & 9.27 \\
\hline
\end{tabular}


for normal mode calculation purposes, the repeat unit has 13 atoms and 49 internal coordinates compared to 10 atoms and 39 internal coordinates in $\alpha$-poly(L-alanine). ${ }^{21}$ The optically active modes are classified into $\mathrm{A}\left(\delta=0^{\circ}\right), \mathrm{E}_{1}(\delta=\theta)$, and $\mathrm{E}_{2}(\delta=2 \theta)$ symmetry species, where $\delta$ is the phase difference between the motions in adjacent residues and $\theta$ is the angle of rotation per chemical residue about the helical axis; the value of $\theta$ is $120^{\circ}, 99.57^{\circ}$, and $90^{\circ}$ for $3_{10}, \alpha$, and $\alpha^{\prime}$, respectively. Since $\theta=120^{\circ}$ for the $3_{10^{-h e l i x}}$, the $\mathrm{E}_{1}$ and $\mathrm{E}_{2}$ species are degenerate and therefore we report only $A$ and $E_{1}$ modes for this structure. The number of modes in each symmetry species and their optical activity for each structure are as follows: $3_{10}$ : $\mathrm{A}\left(\right.$ Raman, $\left.\mathrm{ir}_{\|}\right)-37, \mathrm{E}_{1}(\mathrm{Raman}$, $\left.\mathrm{ir}_{1}\right)-38 ; \alpha$ : A(Raman, $\left.\mathrm{ir}_{\|}\right)-37, \mathrm{E}_{1}\left(\operatorname{Raman}_{\mathrm{ir}}\right)-38, \mathrm{E}_{2}(\operatorname{Raman})-39$; and $\alpha^{\prime}: \mathrm{A}\left(\right.$ Raman, $\left.\mathrm{ir}_{\|}\right)-37, \mathrm{E}_{1}\left(\right.$ Raman, $\left.\mathrm{ir}_{1}\right)-38, \mathrm{E}_{2}($ Raman $)-39$.

\section{Force Field}

As a starting point, we transferred without change all the necessary force constants from $\alpha$-poly(L-alanine), ${ }^{21}$ even though we recognized that the presence in PAIB of a $\mathrm{CH}_{3}$ group in place of $\mathrm{H}^{\alpha}$ would result in different interactions around $\mathrm{C}^{\alpha}$. This force field was used to compute the frequencies and their potential energy distributions (PED) for the three structural models.

In general, the fit to the experimental data was very satisfactory, with only those modes having the larger contribution from the $\mathrm{CH}_{3}$ (2) group showing some discrepancies. Besides such discrepancies common to all the structures, a detailed comparison showed that the computed frequencies for the $3_{10}$-helix were generally in better agreement with the observed values. For instance, the amide $\mathrm{V}$ mode observed at $694\left(\mathrm{ir}_{1}\right)$ and $680\left(\mathrm{ir}_{\|}\right)$was predicted at $699\left(\mathrm{E}_{1}\right)$ and $672(\mathrm{~A})$ by the $3_{10}$-helix, at $656\left(\mathrm{E}_{1}\right)$ and $629(\mathrm{~A})$ by the $\alpha$-helix, and at $625\left(\mathrm{E}_{1}\right)$ and 619 (A) $\mathrm{cm}^{-1}$ by $\alpha^{\prime}$-helix. A mixed mode (CN stretch $+\mathrm{CC}_{2}$ asymmetric stretch $+\mathrm{CH}_{3}$ rock) observed at $1214(\mathrm{R})$ and $1210\left(\mathrm{ir}_{\|}\right)$was predicted at $1194(\mathrm{~A}), 1177(\mathrm{~A})$, and $1186(\mathrm{~A}) \mathrm{cm}^{-1}$ by the $3_{10^{-}}, \alpha-$, and $\alpha^{\prime}$-helices, respectively. Apart from these prominent differences, there were about 10 more cases in which, although the differences were not as large, the $3_{10}$-helix gave better agreement. We therefore used the $3_{10}$-helix in making slight adjustments in the force constants that influence the $\mathrm{CC}_{2}\left[\mathrm{C}^{\alpha}\left(\mathrm{CH}_{3}\right)_{2}\right]$ group (these changes are essentially independent of conformation).

A total of 25 force constants (Table II) required alteration. Of these, the changes in five force constants, namely, $f(\mathrm{CO}), f(\mathrm{NH}), f(\mathrm{H} \cdots \mathrm{O})$, $f(\mathrm{CO} \mathrm{ob})$, and $f(\mathrm{NH} \cdots \mathrm{O} \mathrm{t})$, reflect differences in hydrogen-bond geometry and strength between the $3_{10^{-}}$and $\alpha$-helices. The final values of these constants were obtained by manual adjustment. For example, the unperturbed amide A $\left(v_{A}^{0}\right)$ mode for PAIB is at $\sim 3260 \mathrm{~cm}^{-1}$ (see Results and Discussion), which happens to be the mean of $v_{A}^{0}$ values 
TABLE II

Modified Force Constants Appropriate to Poly(a-Aminoisobutyric Acid)

\begin{tabular}{|c|c|}
\hline Force Constant & Value \\
\hline$f(\mathrm{CO})$ & 9.955 \\
\hline$f(\mathrm{NH})$ & 5.752 \\
\hline$f(\mathbf{H} \ldots \mathrm{O})$ & 0.135 \\
\hline$f(\mathrm{CO} \mathrm{ob})$ & 0.687 \\
\hline$f(\mathrm{NH} \cdots \mathrm{Ot})$ & 0.0003 \\
\hline$f\left(\mathrm{C}^{\beta} \mathrm{C}^{\alpha} \mathrm{C}^{\beta}\right)$ & 1.181 \\
\hline$f\left(\mathrm{C}^{\alpha} \mathrm{C}^{\beta} \mathrm{t}\right)$ & 0.090 \\
\hline$f\left(\mathrm{C}^{a} \mathrm{C}, \mathrm{C}^{a} \mathrm{C}^{\beta}\right)$ & 0.301 \\
\hline$f\left(\mathrm{C}^{a} \mathrm{C}^{\beta}, \mathrm{C}^{a} \mathrm{C}^{\beta}\right)$ & 0.100 \\
\hline$f\left(\mathrm{NC}^{\alpha}, \mathrm{C}^{\beta} \mathrm{C}^{\alpha} \mathrm{C}^{\beta}\right)$ & 0.200 \\
\hline$f\left(\mathrm{C}^{\alpha} \mathrm{C}, \mathrm{NC}^{\alpha} \mathrm{C}^{\beta}\right)$ & 0.100 \\
\hline$f\left(\mathrm{C}^{\alpha} \mathrm{C}^{\beta}(1), \mathrm{NC}^{\alpha} \mathrm{C}^{\beta}(2)\right)$ & 0.030 \\
\hline$f\left(\mathrm{C}^{\alpha} \mathrm{C}^{\beta}(1), \mathrm{CC}^{\alpha} \mathrm{C}^{\beta}(2)\right)$ & 0.030 \\
\hline$f\left(\mathrm{C}^{\alpha} \mathrm{C}^{\beta}, \mathrm{C}^{\beta} \mathrm{C}^{\alpha} \mathrm{C}^{\beta}\right)$ & 0.517 \\
\hline$f\left(\mathrm{C}^{a} \mathrm{C}^{\beta}, \mathrm{C}^{a} \mathrm{C}^{\beta} \mathrm{H}\right)$ & 0.403 \\
\hline$f\left(\mathrm{C}^{a} \mathrm{CO}, \mathrm{CC}^{\alpha} \mathrm{C}^{\beta}\right)$ & 0.200 \\
\hline$f\left(\mathrm{CNC}^{\alpha}, \mathrm{NC}^{a} \mathrm{C}^{\beta}\right)$ & 0.100 \\
\hline$f\left(\mathrm{C}^{\alpha} \mathrm{NH}, \mathrm{NC}^{\alpha} \mathrm{C}^{\beta}\right)$ & 0.050 \\
\hline$f\left(\mathrm{NC}^{\alpha} \mathrm{C}, \mathrm{NC}^{\alpha} \mathrm{C}^{\beta}\right)$ & 0.100 \\
\hline$f\left(\mathrm{NC}^{\alpha} \mathrm{C}^{\beta}, \mathrm{C}^{\beta} \mathrm{C}^{\alpha} \mathrm{C}^{\beta}\right.$ & -0.031 \\
\hline$f\left(\mathrm{NC}^{a} \mathrm{C}^{\beta}, \mathrm{NH}\right.$ ob $)$ & 0.060 \\
\hline$f\left(\mathrm{CC}^{\alpha} \mathrm{C}^{\beta}, \mathrm{CC}^{\alpha} \mathrm{C}^{\beta}\right)$ & 0.100 \\
\hline$f\left(\mathrm{CC}^{\alpha} \mathrm{C}^{\beta}, \mathrm{C}^{\beta} \mathrm{C}^{\alpha} \mathrm{C}^{\beta}\right)$ & -0.031 \\
\hline$f\left(\mathrm{C}^{\beta} \mathrm{C}^{\alpha} \mathrm{C}^{\beta}, \mathrm{C}^{\alpha} \mathrm{C}^{\beta} \mathrm{H}\right)_{\mathrm{T}}$ & 0.100 \\
\hline$f\left(\mathrm{C}^{\beta} \mathrm{C}^{\alpha} \mathrm{C}^{\beta}, \mathrm{C}^{\alpha} \mathrm{C}^{\beta} \mathrm{H}\right)_{\mathrm{G}}$ & 0.010 \\
\hline
\end{tabular}

for $\alpha$ - and $\beta$-poly(L-alanine) ${ }^{34}$ This indicates that the hydrogen-bond strength in PAIB is intermediate between those for the $\alpha$ - and $\beta$ structures, which is also supported by the structural data $[r(\mathrm{~N} \cdots \mathrm{O})$ for the $\beta$-structure is $2.731 \AA^{20}$. We therefore took for the values of $f(\mathrm{CO}), f(\mathrm{NH})$, and $f(\mathrm{H} \ldots \mathrm{O})$ the mean of the corresponding values for the $\alpha$-helical ${ }^{21}$ and $\beta$-sheet ${ }^{20}$ structures. The remaining force constants in Table II are associated with the $\mathrm{CC}_{2}$ group and were refined by a least-squares method. Dispersions in these force constants in the range of $0.1-0.6$ average $5 \%$. It is interesting that the force constants associated with the backbone of the chain did not require any alteration, confirming the fact that the conformations of $\alpha$ - and $3_{10}$-helices are very close. ${ }^{4}$ Although the above force constants were refined for the $3_{10}$-helix, they also improved the fit between theoretical and experimental values when used for $\alpha$ and $\alpha^{\prime}$ in the final calculations. For a complete force field for PAIB, readers will require all the relevant force constants from our work, ${ }^{20,21}$ as well as the 25 constants listed in Table II of this paper. This force field has been used to compute the frequencies of the $3_{10}, \alpha$-, and $\alpha^{\prime}$-helical structural models for PAIB and the corresponding $\mathrm{N}$-deuterated derivatives.

It should be noted that, as in our earlier work, ${ }^{18,21}$ transition dipole 
coupling interactions were used to calculate the splittings in amide I and II modes. In the $3_{10}$-helix, contributions to the $\mathrm{A}$ and $\mathrm{E}_{1}$ species for amide I are -2.3 and $-3.3 \mathrm{~cm}^{-1}$, respectively, and for amide II, -6.6 and $5.9 \mathrm{~cm}^{-1}$, respectively. In the $\alpha$-helix, contributions to $\mathrm{A}, \mathrm{E}_{1}$, and $\mathrm{E}_{2}$ species for amide $\mathrm{I}$ are $-5.5,-7.2$, and $-16.8 \mathrm{~cm}^{-1}$, respectively, and for amide II, $-9.6,6.2$, and $4.2 \mathrm{~cm}^{-1}$, respectively. For the $\alpha^{\prime}$-helix such contributions are $-0.8,-1.3$, and $-19.2 \mathrm{~cm}^{-1}$, and -8.4 , 4.6 , and $6.0 \mathrm{~cm}^{-1}$, respectively. Since the transition dipole parameters are the same, these variations result from the conformational differences between the three structures. The detailed results are discussed in the following section.

\section{RESULTS AND DISCUSSION}

\section{Poly( $\alpha$-Aminoisobutyric Acid)}

We present in Fig. 1 the polarized ir spectra of PAIB and PAIB-ND, and in Fig. 2 the Raman spectra of these materials-in both cases,

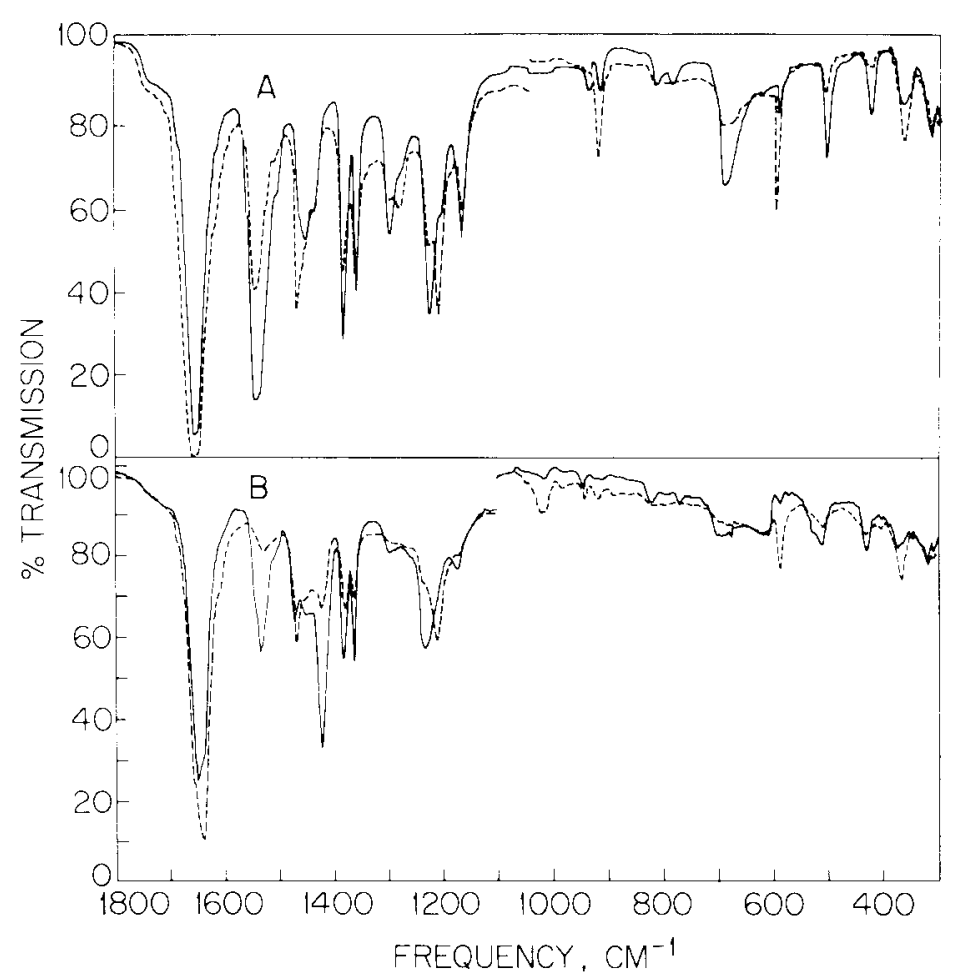

Fig. 1. Polarized ir spectra of (A) poly( $\alpha$-aminoisobutyric acid) and (B) poly( $\alpha$-aminoisobutyric acid-ND): Electric vector perpendicular to orientation direction (-) and electric vector parallel to orientation direction (- - ). 


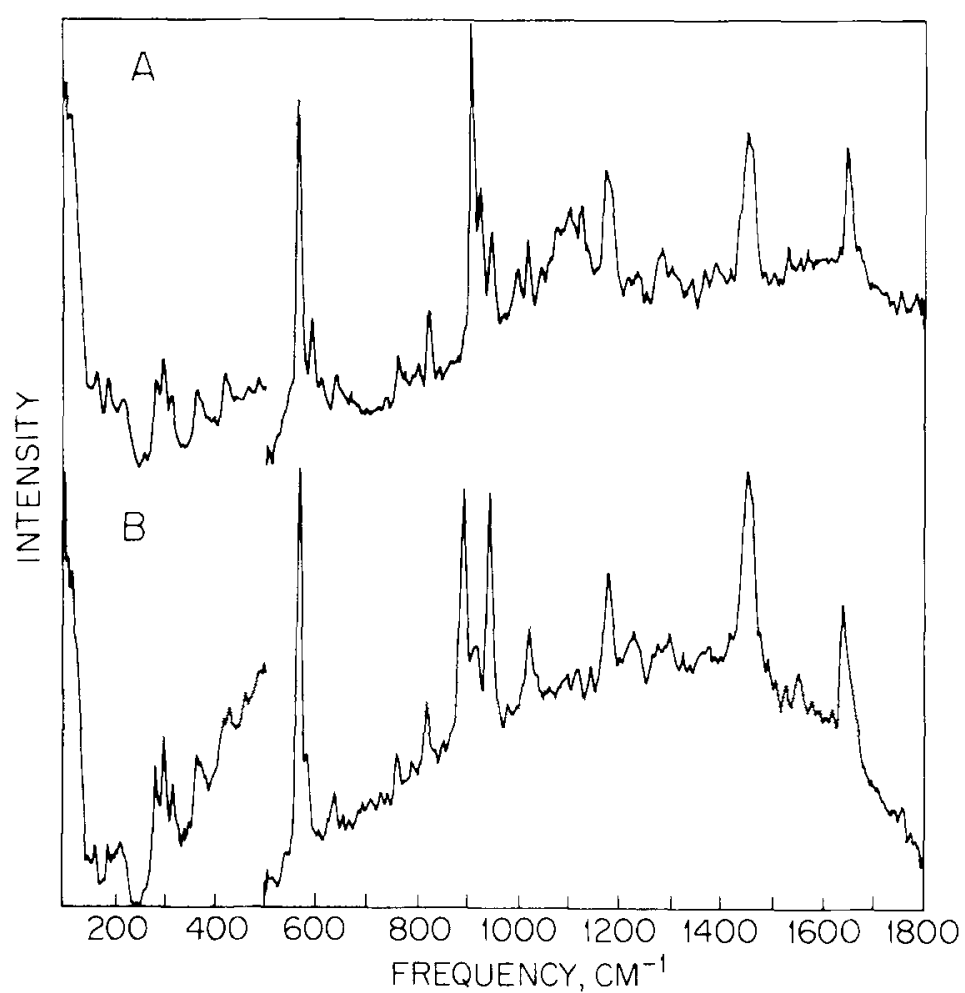

Fig. 2. Raman spectra of (A) poly( $\alpha$-aminoisobutyric acid) and (B) poly( $\alpha$-aminoisobutyric acid-ND).

thin films prepared by the Langmuir trough technique described above. The observed band frequencies are given in Tables III and IV, together with the calculated frequencies and PEDs of the $3_{10^{-}}, \alpha$-, and $\alpha^{\prime}$-helices.

The NH stretch (amide A) mode is observed at $3272\left(\mathrm{ir}_{1}\right) \mathrm{cm}^{-1}$. This is lower than the values found for $\alpha$-poly(L-alanine $)^{18}\left(3307 \mathrm{~cm}^{-1}\right)$ and $\beta$-poly (L-alanine $)^{34}\left(3276 \mathrm{~cm}^{-1}\right)$, which might suggest that the hydrogen bond in PAIB is stronger than those in the other two structures. However, amide $\mathrm{A}$ is perturbed by Fermi resonance, ${ }^{16,34}$ and therefore, a meaningful conclusion can be drawn only by comparing unperturbed frequencies. The ir spectrum indicates the presence of two amide $B$ modes (of A species, as in the case of amide A), at 3060 and $3030 \mathrm{~cm}^{-1}$. (It might be noted that this is in contrast to the $\alpha$-helix of poly(Lalanine), which exhibits only a single amide $B$ mode at $3058 \mathrm{~cm}^{-1}{ }^{34}$ ) The integrated area ratios of these bands to the amide $\mathrm{A}$ band are 0.0518 and 0.0566 , respectively, leading ${ }^{16,34}$ to unperturbed frequencies of $\nu_{A}^{0}=3262 \mathrm{~cm}^{-1}, \nu_{B}^{0}=3070 \mathrm{~cm}^{-1}$ and $\nu_{A}^{0}=3259 \mathrm{~cm}^{-1}, \nu_{B}^{0}=3043$ $\mathrm{cm}^{-1}$, respectively.

These results lead to some interesting conclusions. The value of 


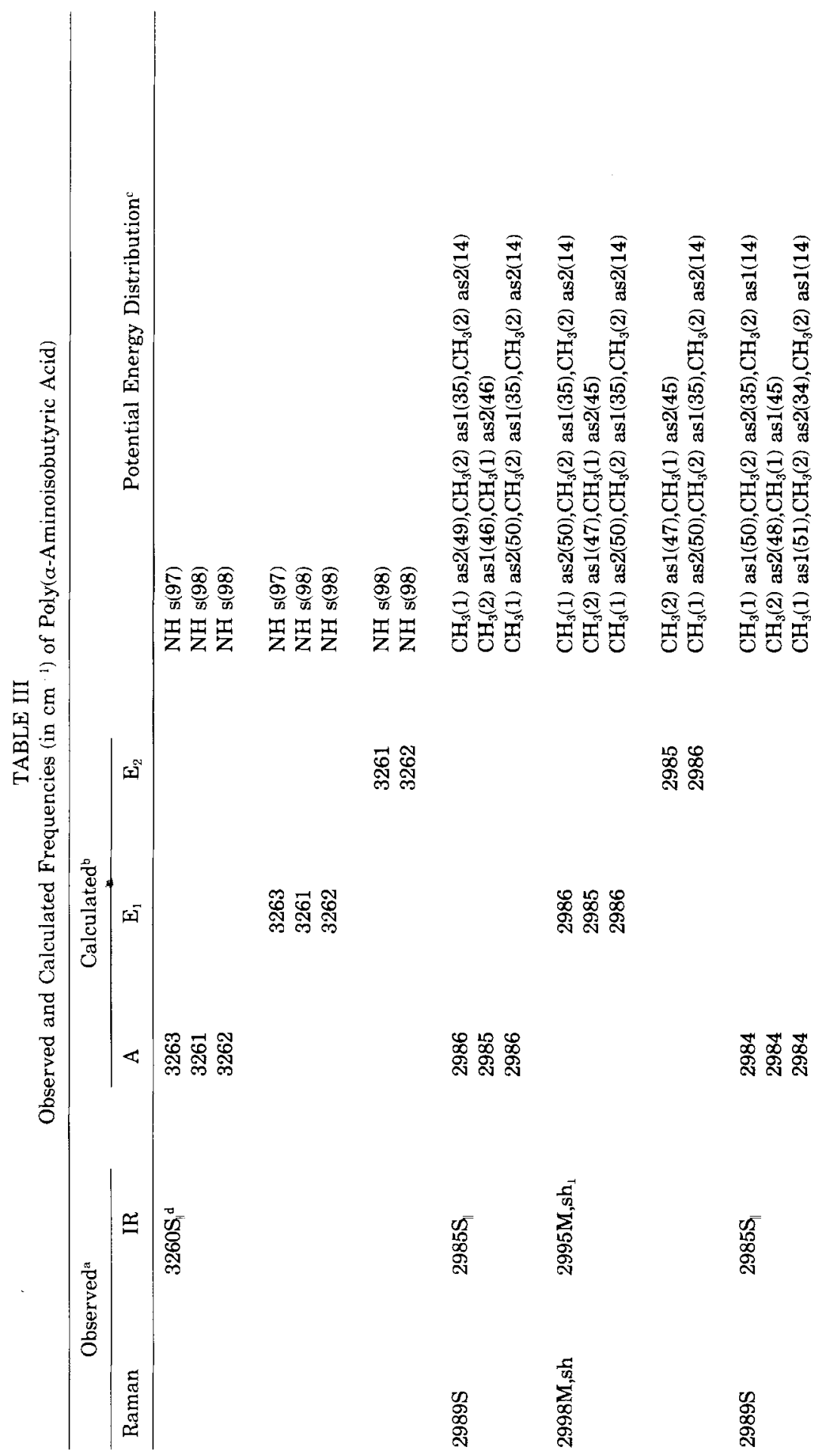




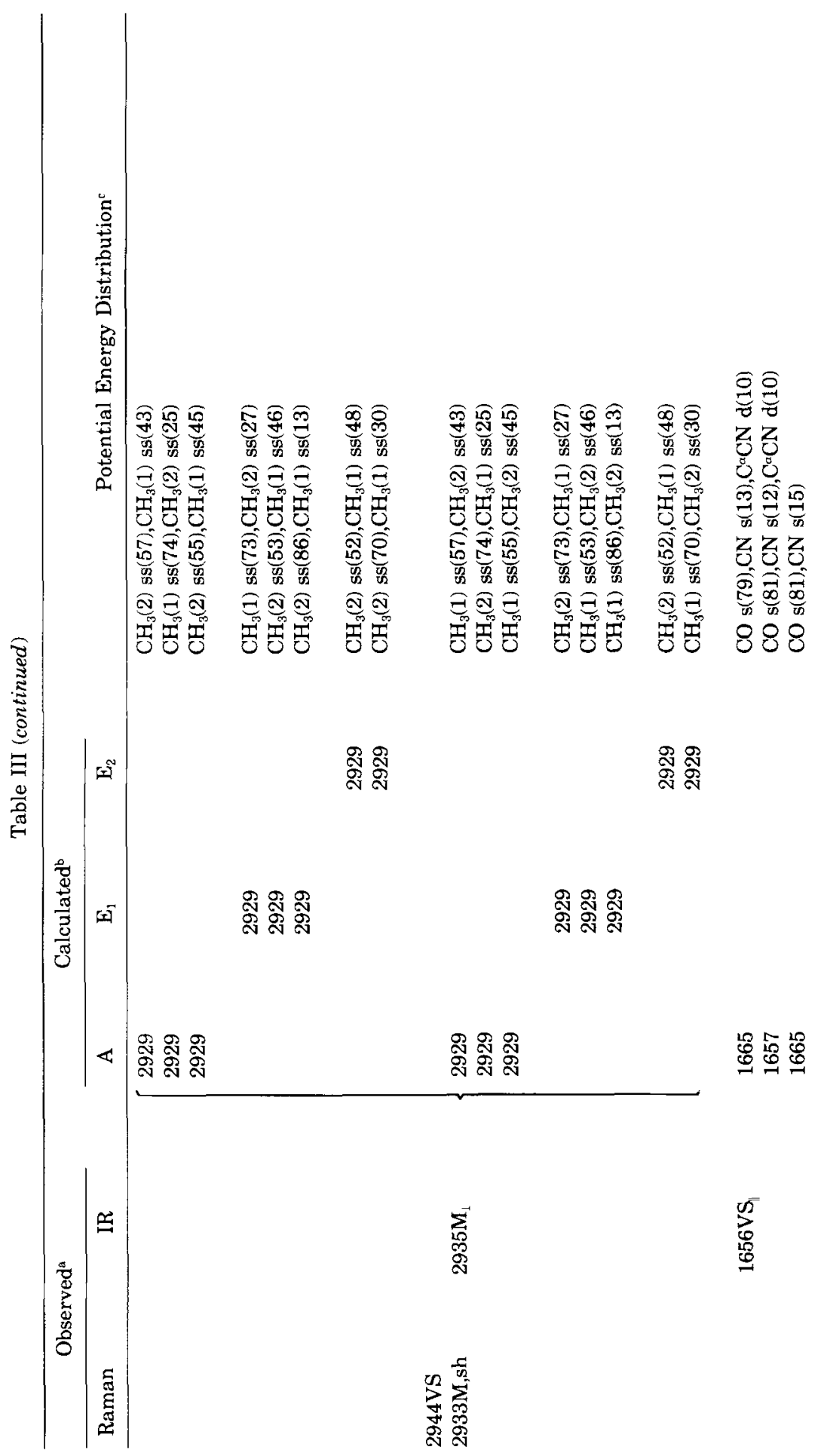




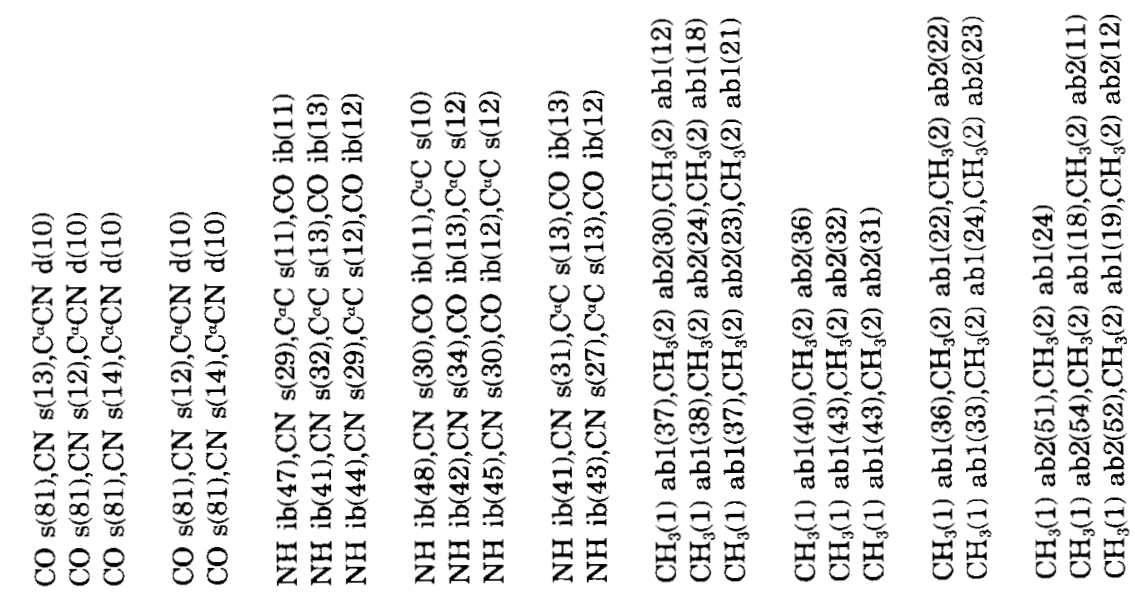
鄫离
㖞啳
量量

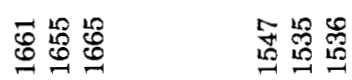

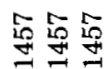

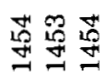

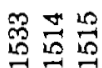

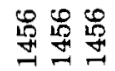

告

$\begin{array}{ll}5 & 5 \\ 10 & 5 \\ 5 & 5\end{array}$

$\frac{2}{5}$

$\frac{3}{10}$

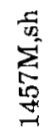




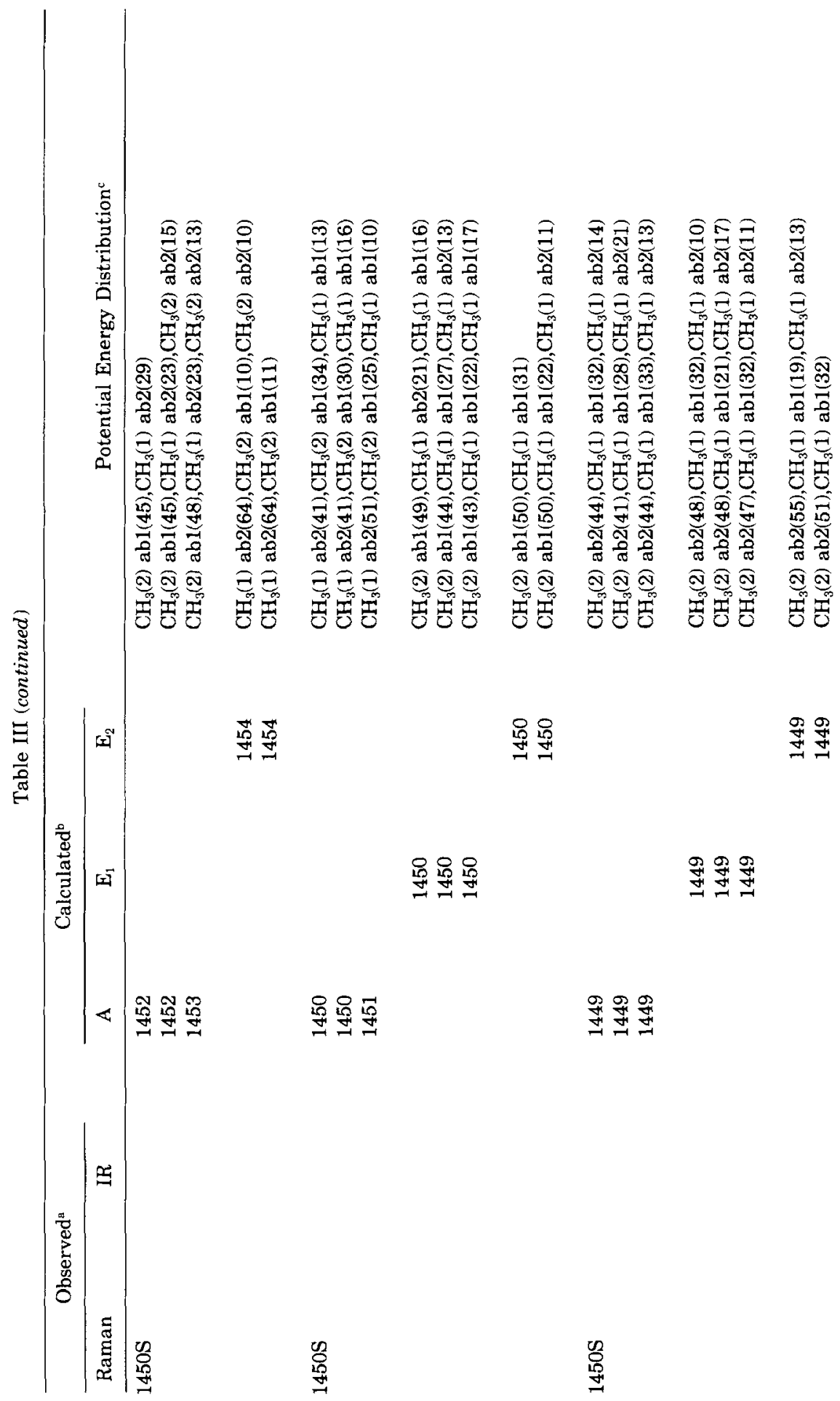




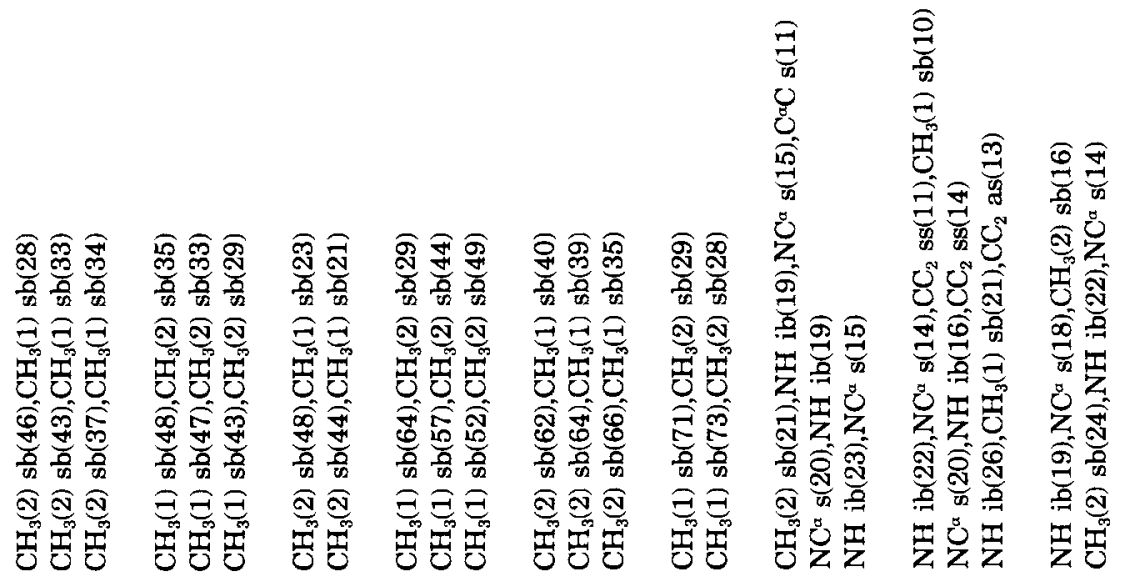

熙总

部

第第

谽器兽

兽嘿兽

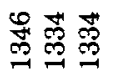

总骂器

电而

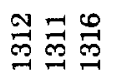

占

5
0
0
-7

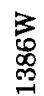

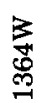

艿 


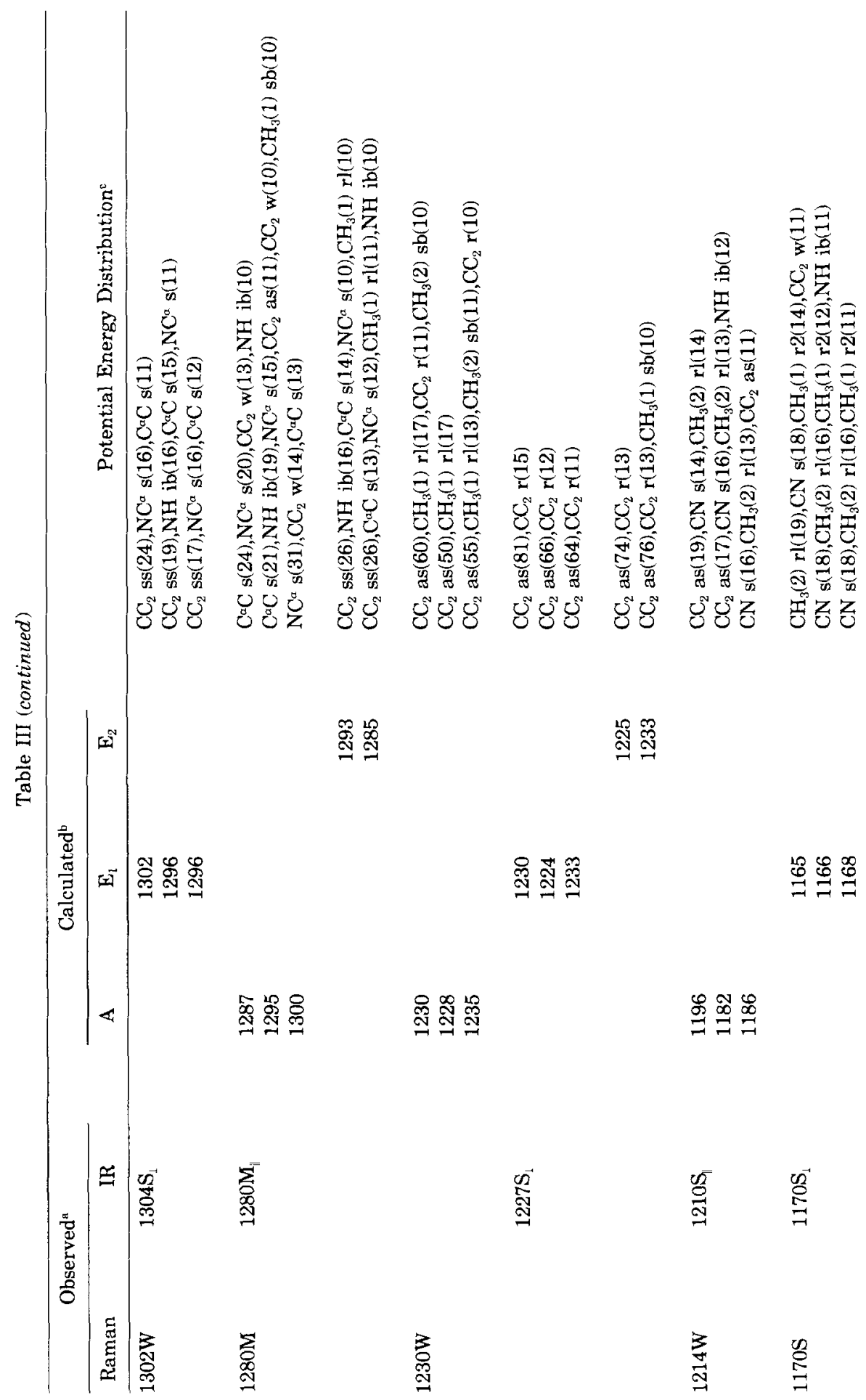


응

芒

อิ จำ

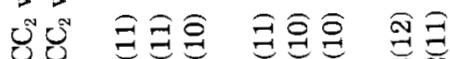

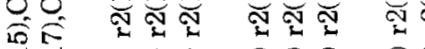

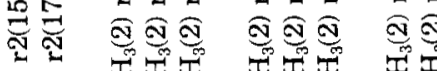

ब亦

음은

突芯芯

空

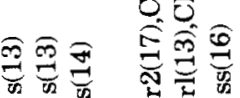

ลิ ลิ

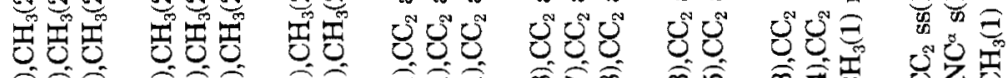

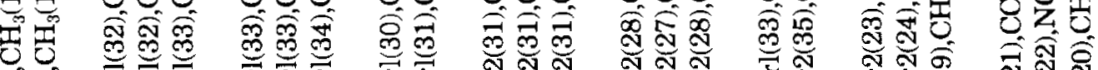

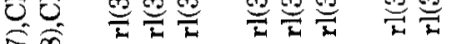

ง

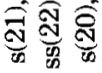

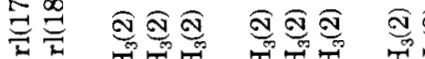

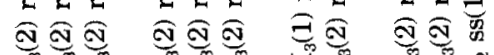

艺艺

ลิ

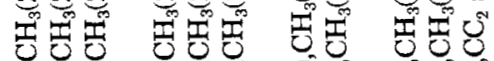

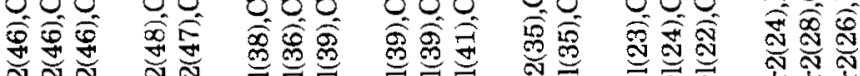

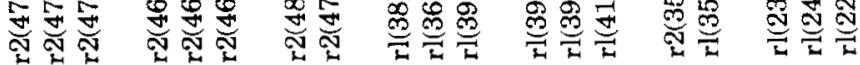

出

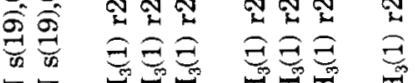

立主

สิ $\widehat{\mathrm{G}}$

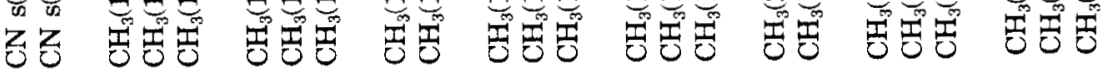

冓骂

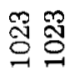

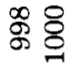

哭 鄂

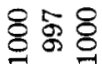

离令胳

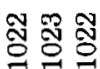

苾第要

我哭器

总

$\sum_{\substack{0 \\ \infty}}^{=}$

$\stackrel{\sum}{\infty}$

$\sum_{\substack{0 \\ 8}}^{3}$

$\sum$ 


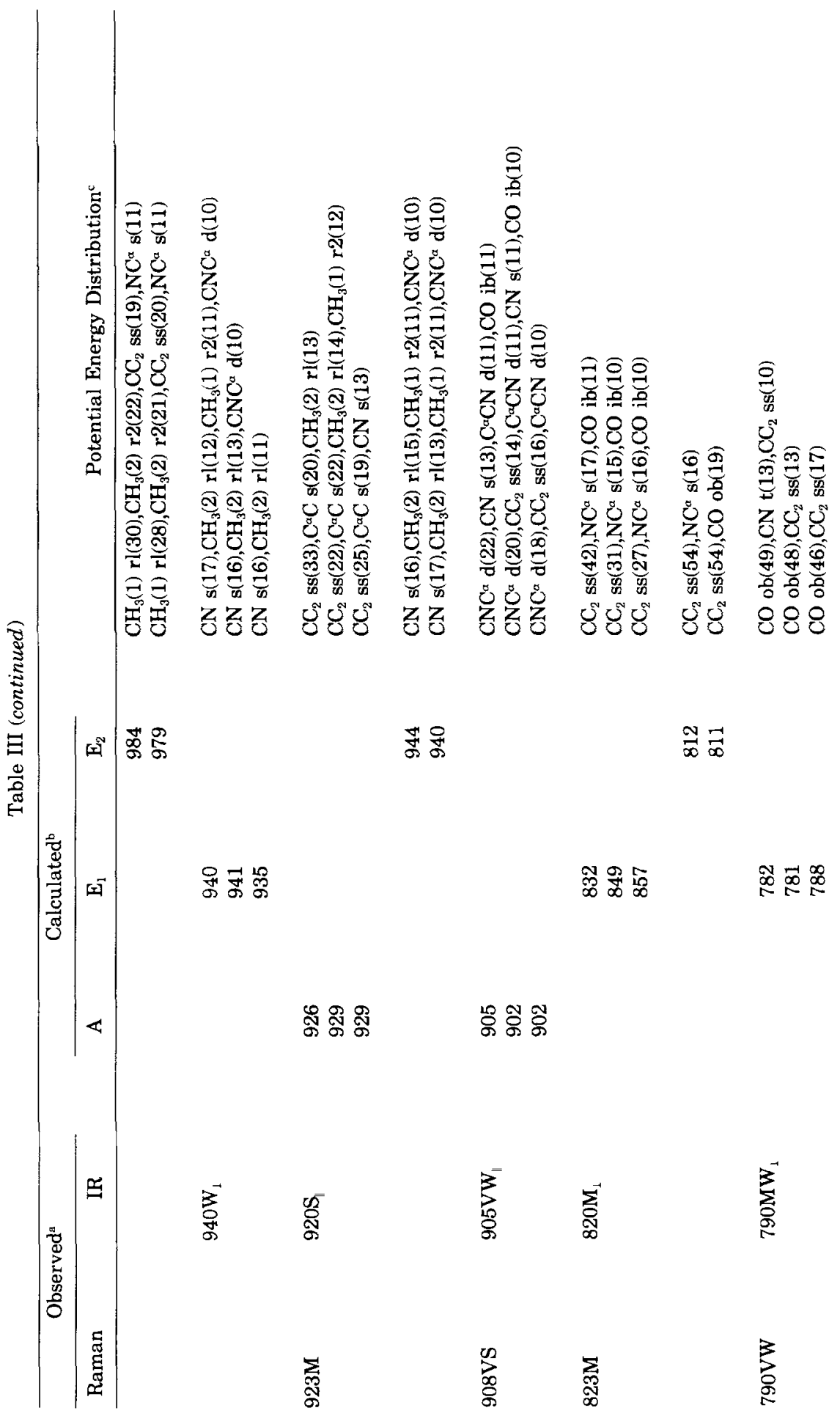




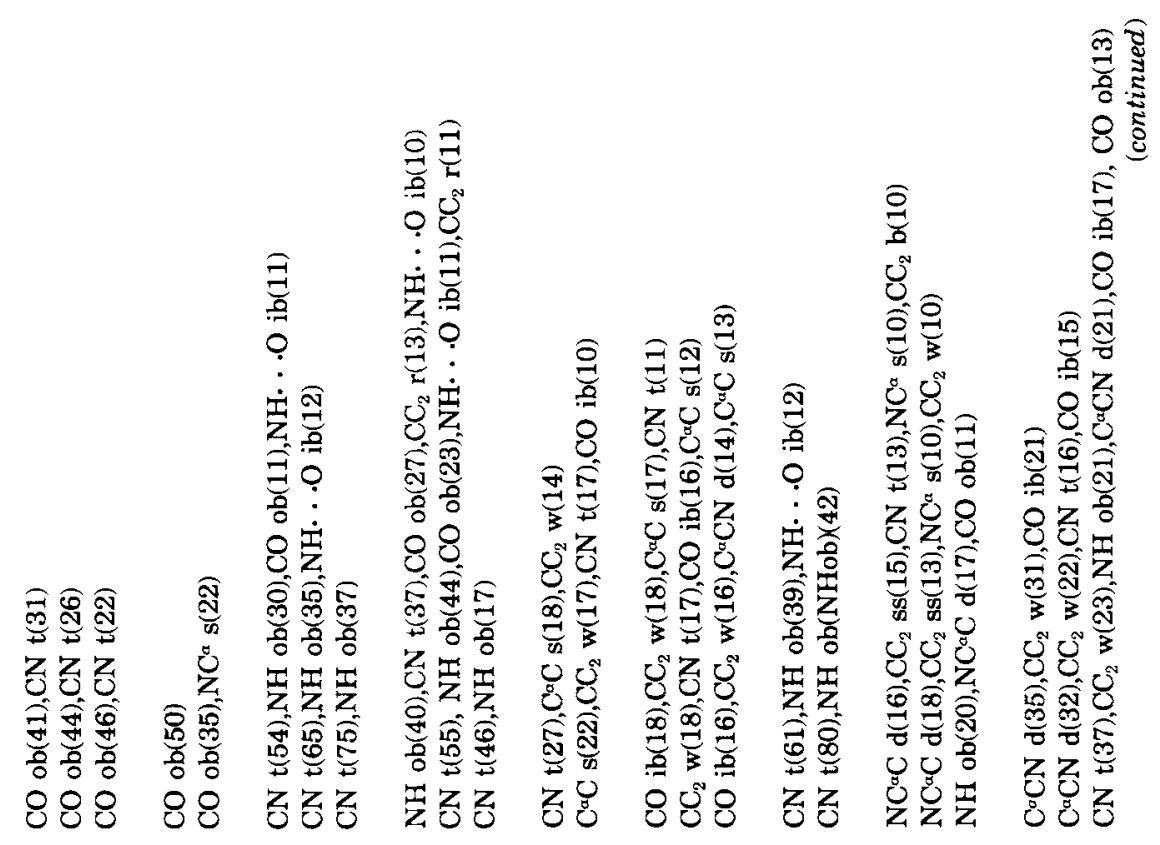

这

冓㴔

눙

호영영

앙 웅 용

象:

용영영

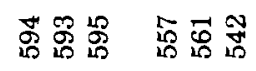

$\underset{\frac{0}{8}}{\frac{0}{8}} \sum_{\substack{0 \\ 0}}^{=}$

离

莕

畓 


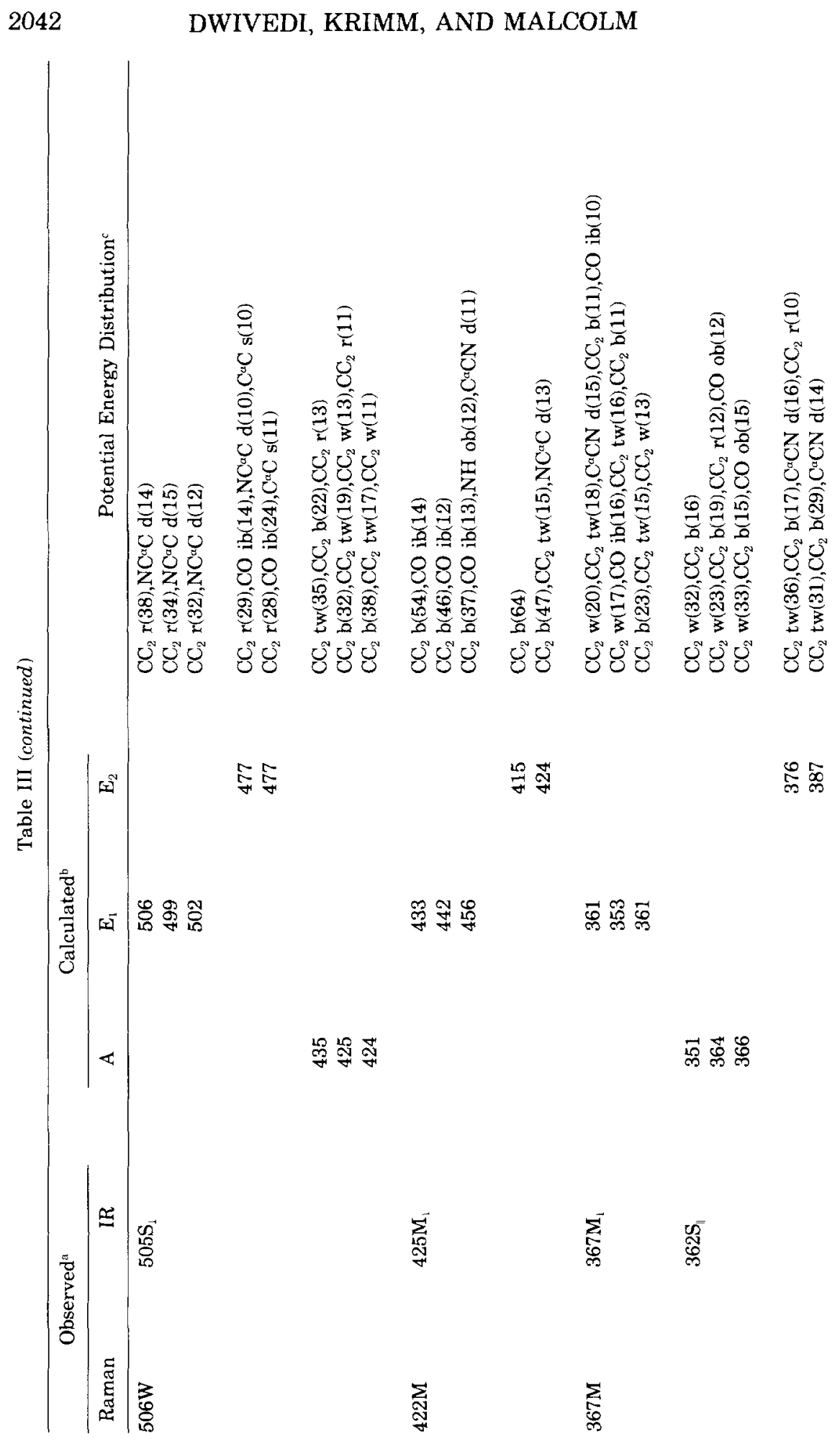




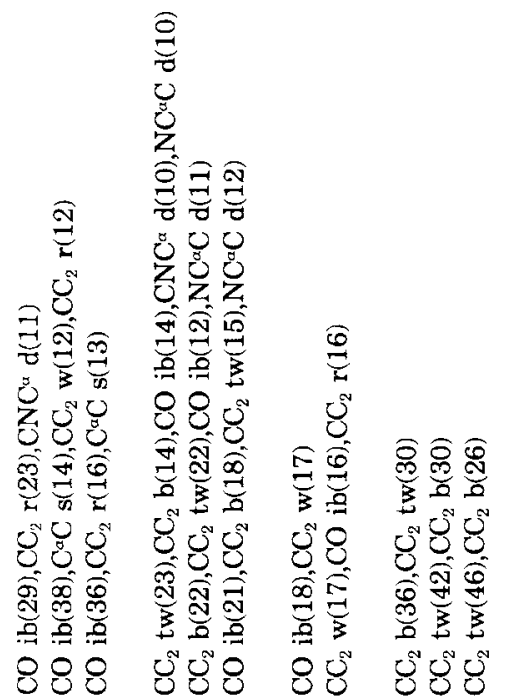

옹

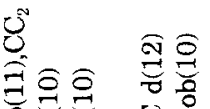

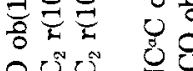

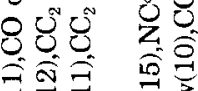

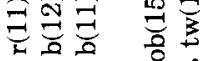
8

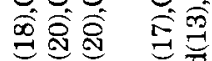

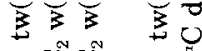

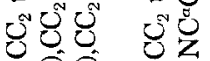

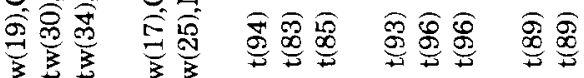
35 3

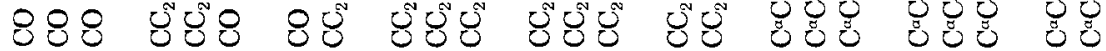

있

कू⿻日禸

ฟึะ

तुํำ

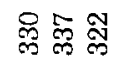

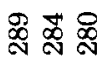

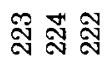
$\sum_{n}^{\infty}$
$\frac{1}{6}$

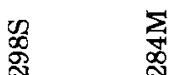
胥 


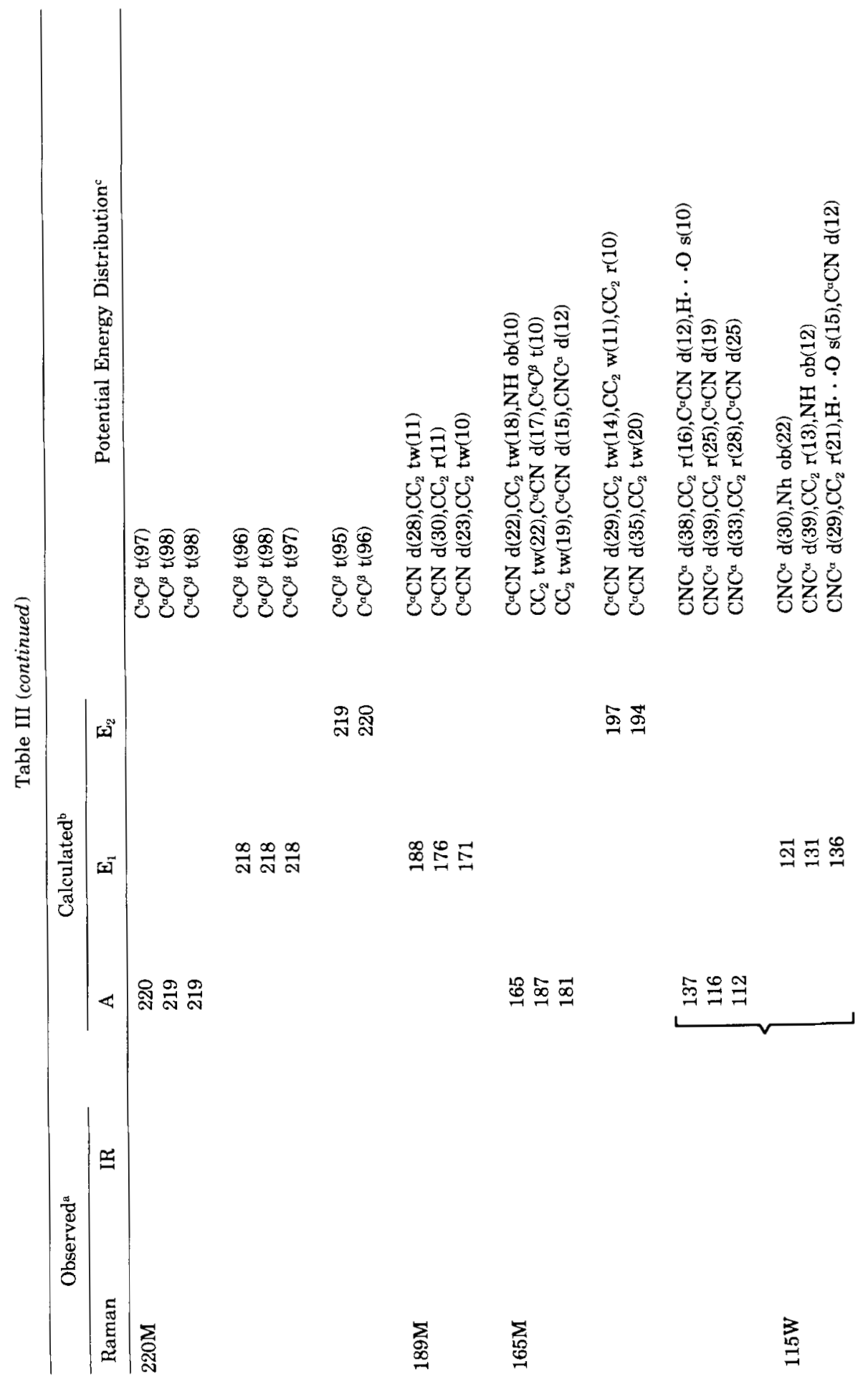




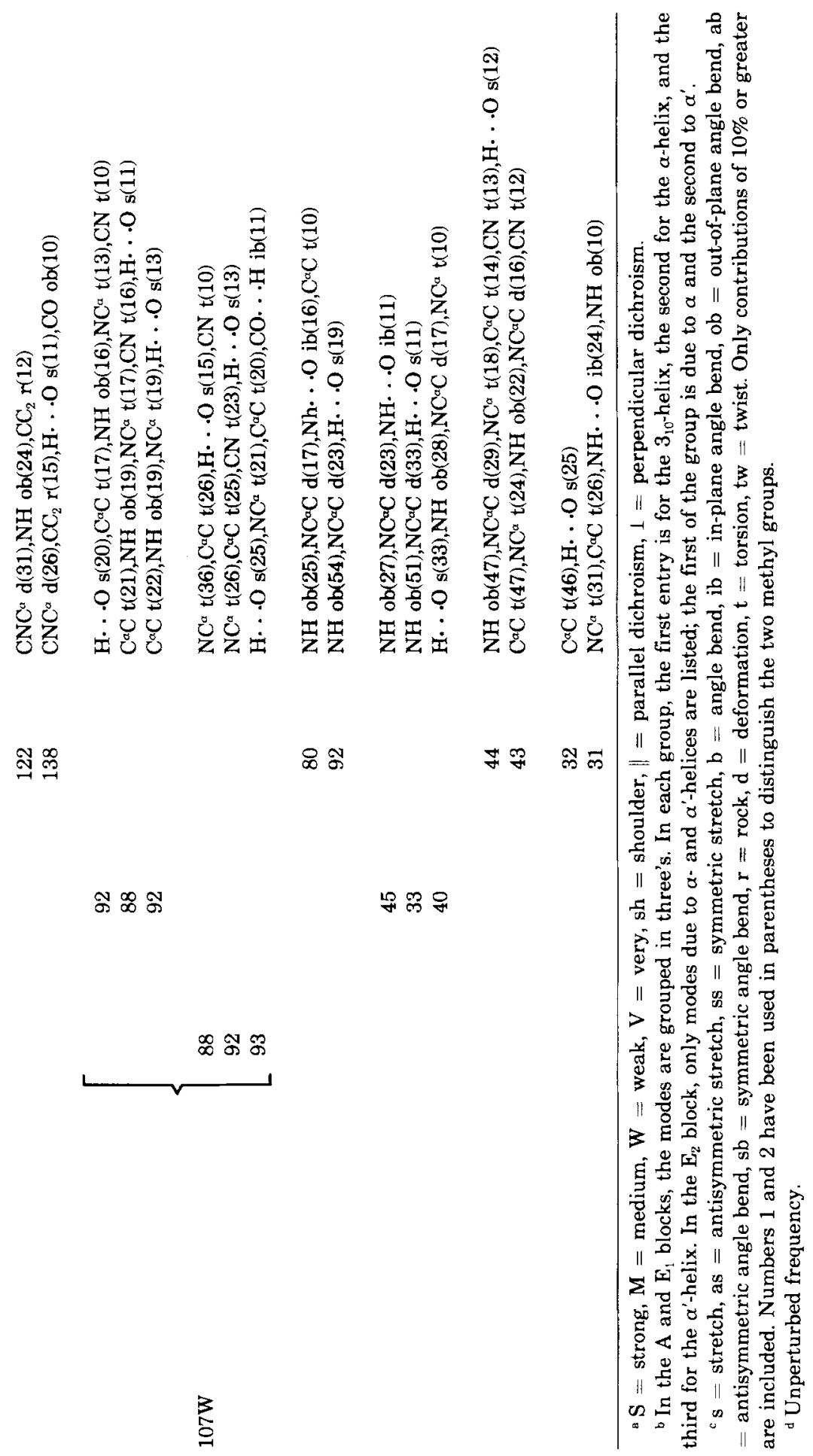




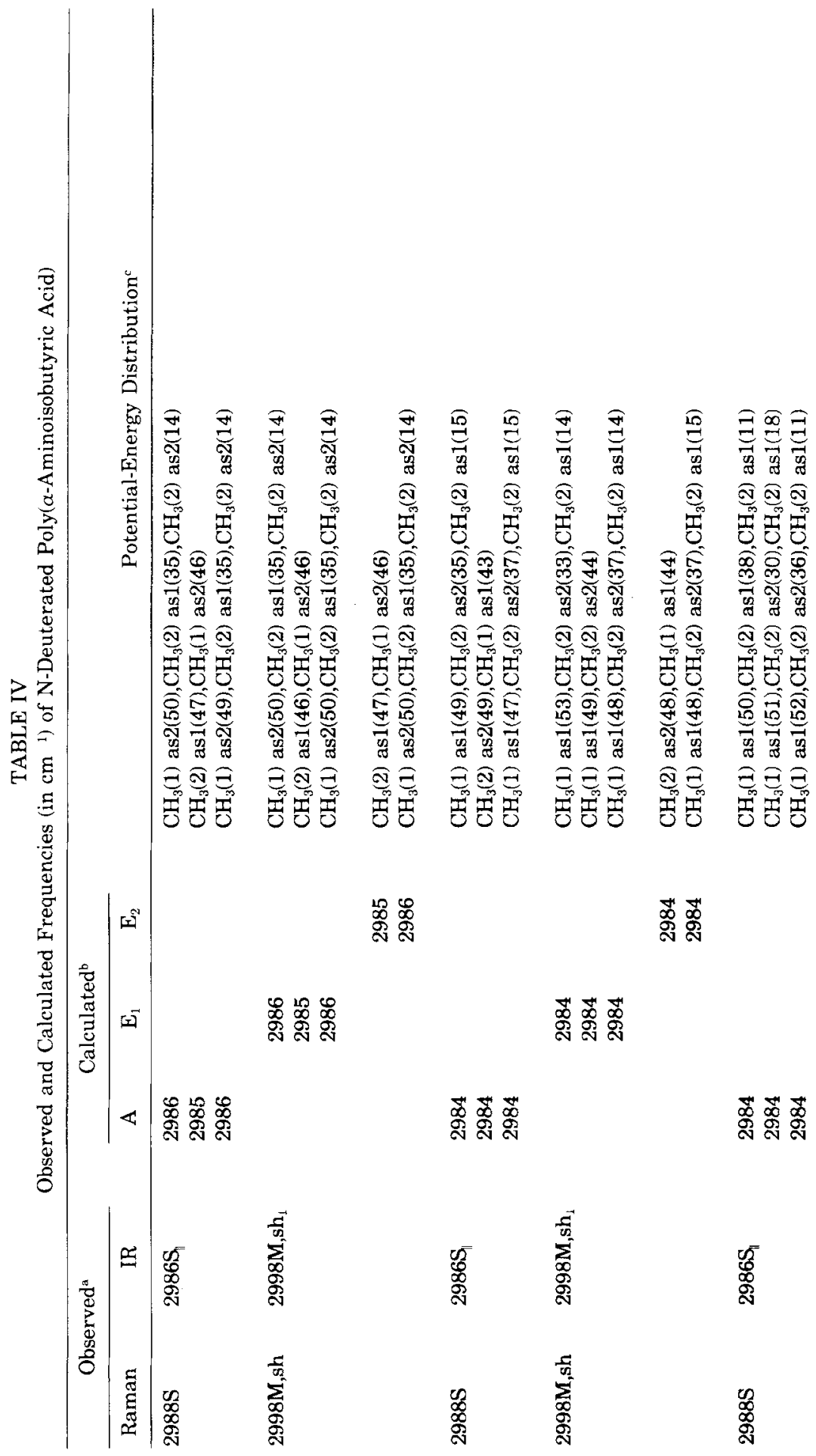




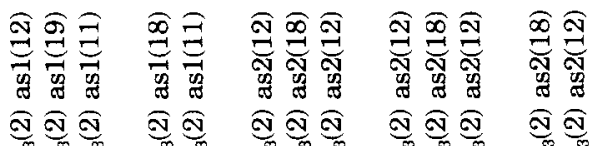

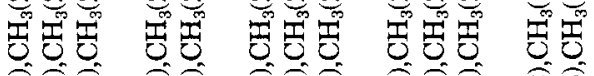

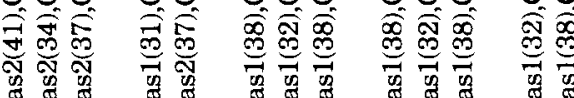

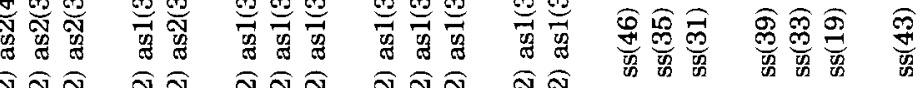

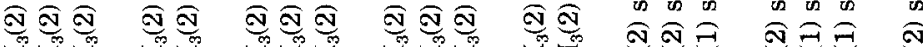

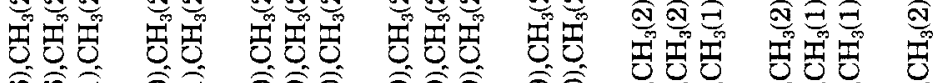

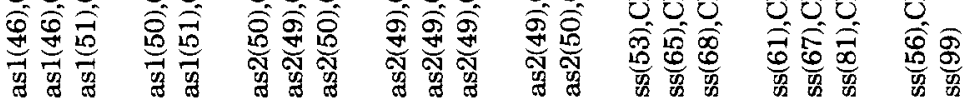

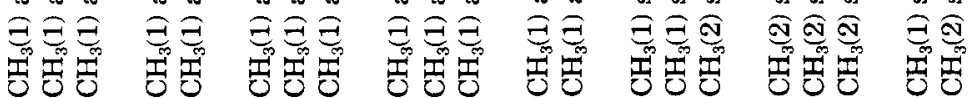

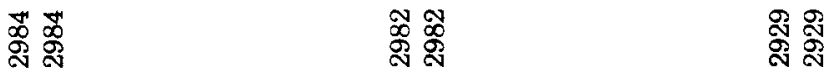

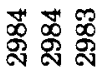

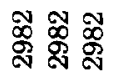

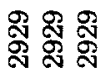

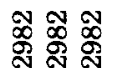

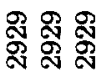

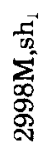

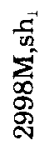

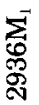

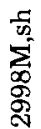

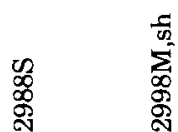

窟 


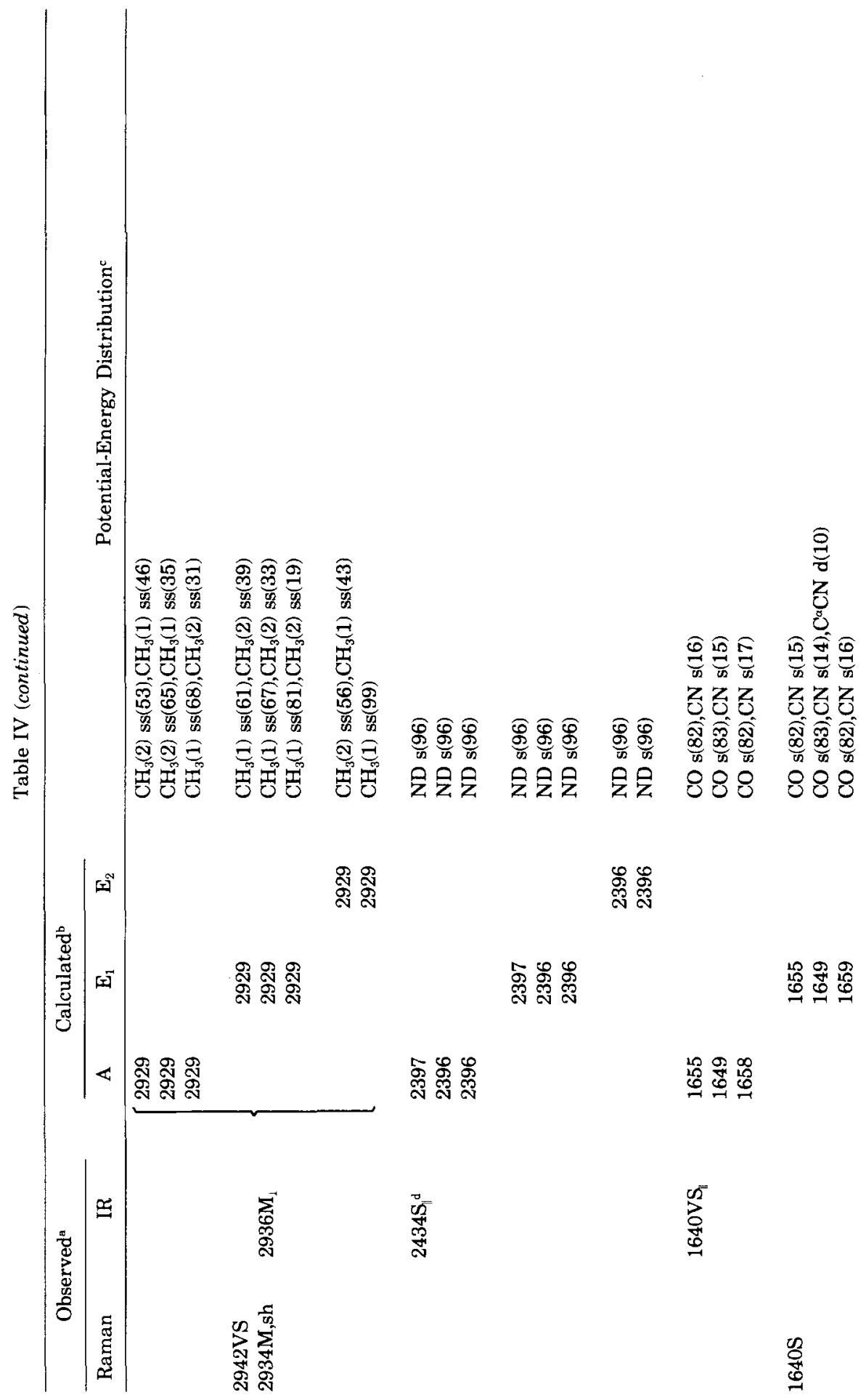




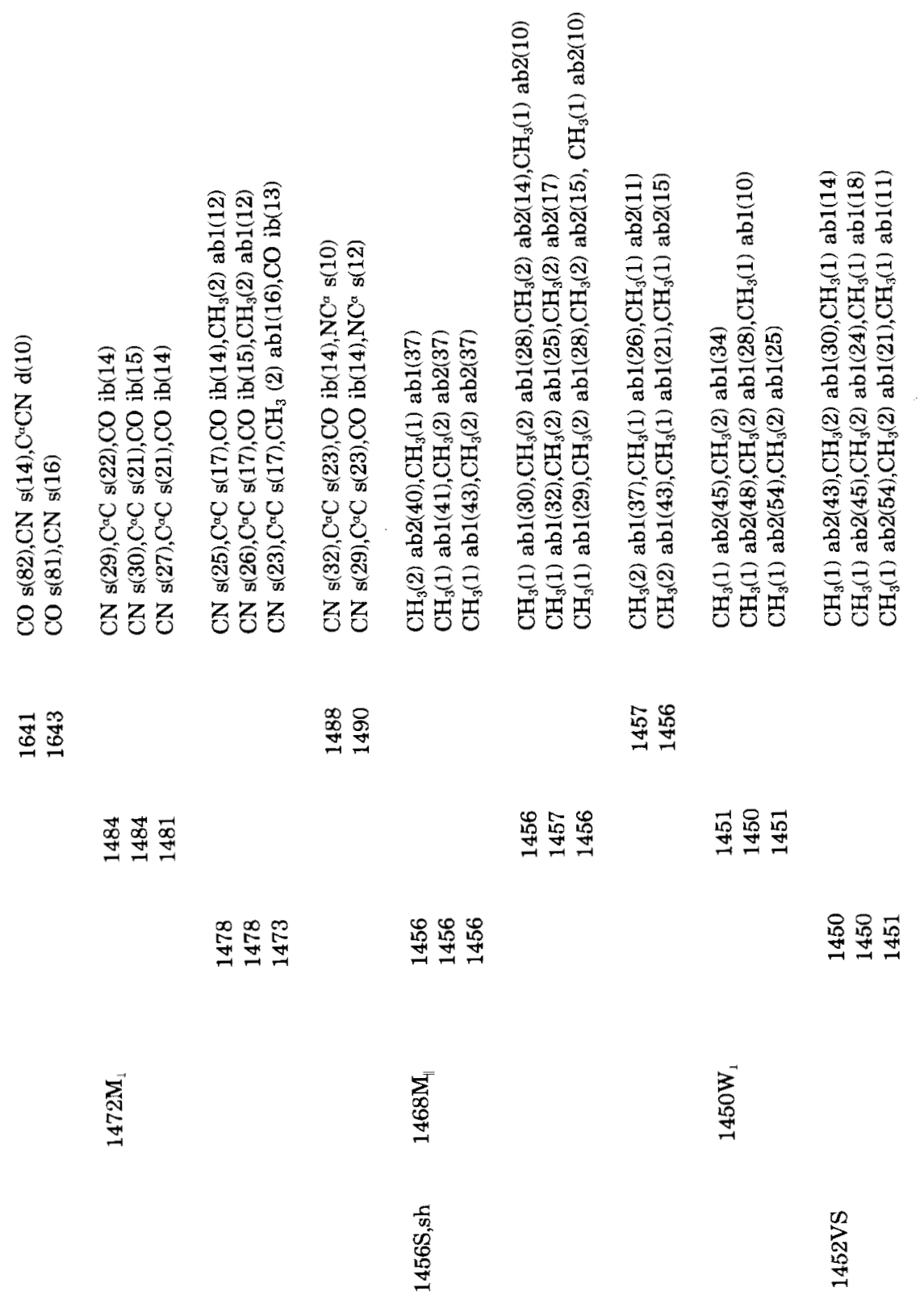




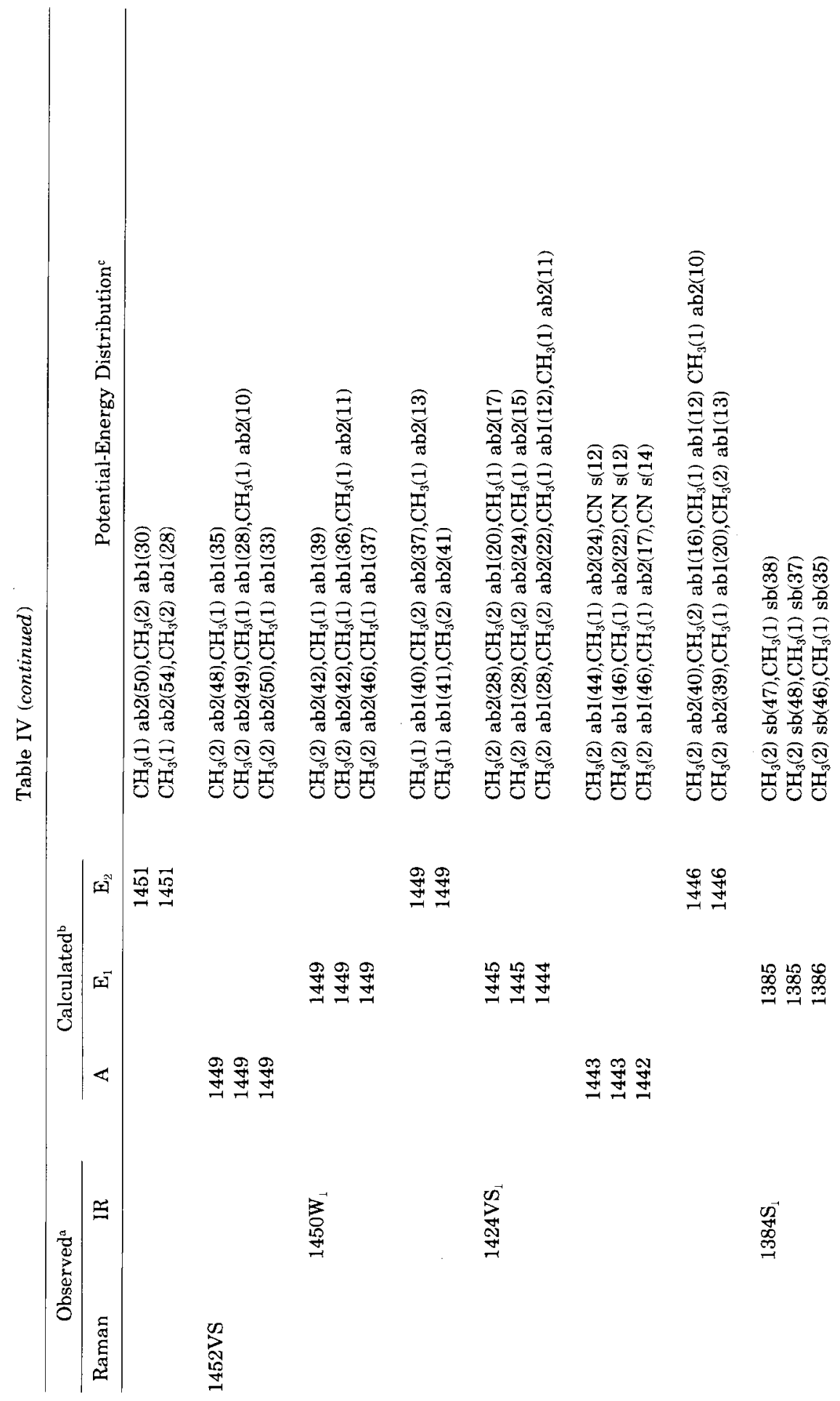




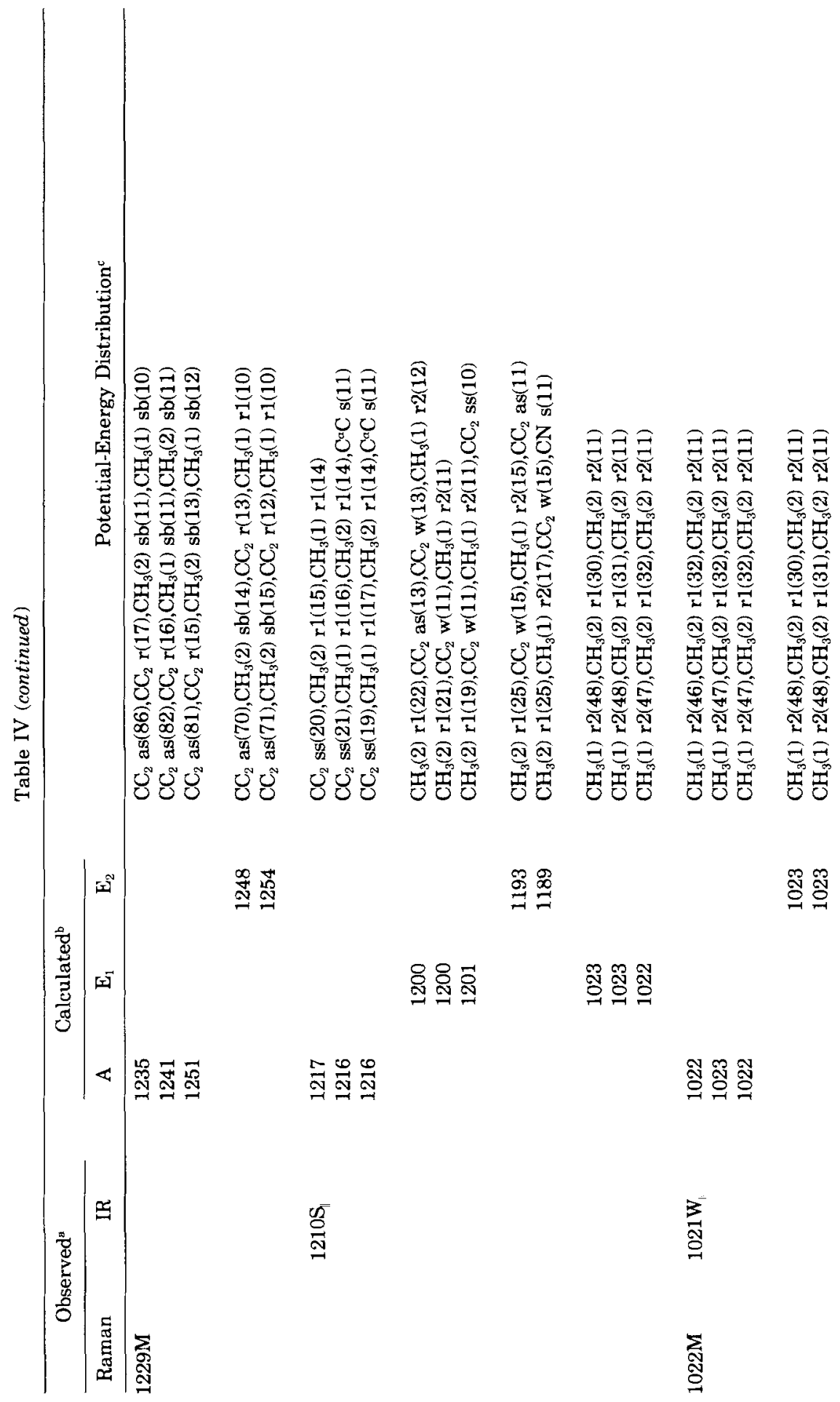




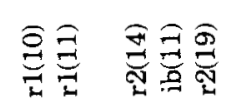

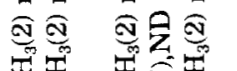

空空

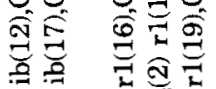

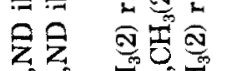

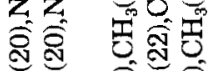

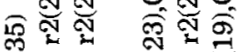

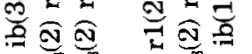

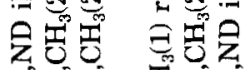

क्षे

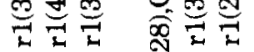

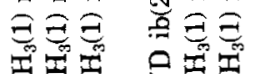

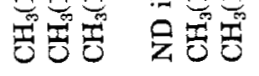

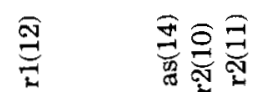

高

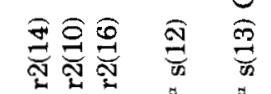

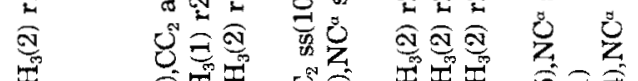

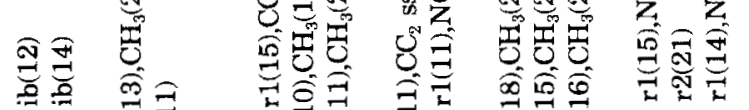

会

열

$\overbrace{4}^{\infty}$

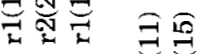

市

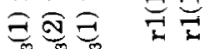

牙

बิง

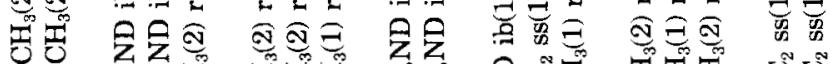

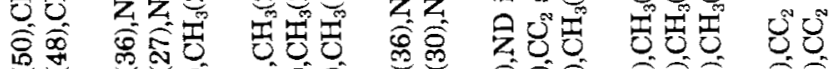

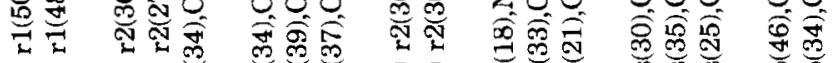

目

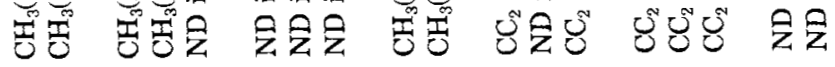
용몸
票需
ㅁㅇㅇ

홍휴:움

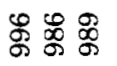

呆导染

总훙뭉

勇恋系

密喿品

$\underset{\frac{\pi}{0}}{3}$

$\sum_{\substack{\infty \\ \infty}}^{=}$

$\frac{5}{5}$

$\frac{5}{8}$

3
$\infty$
$\infty$

告 


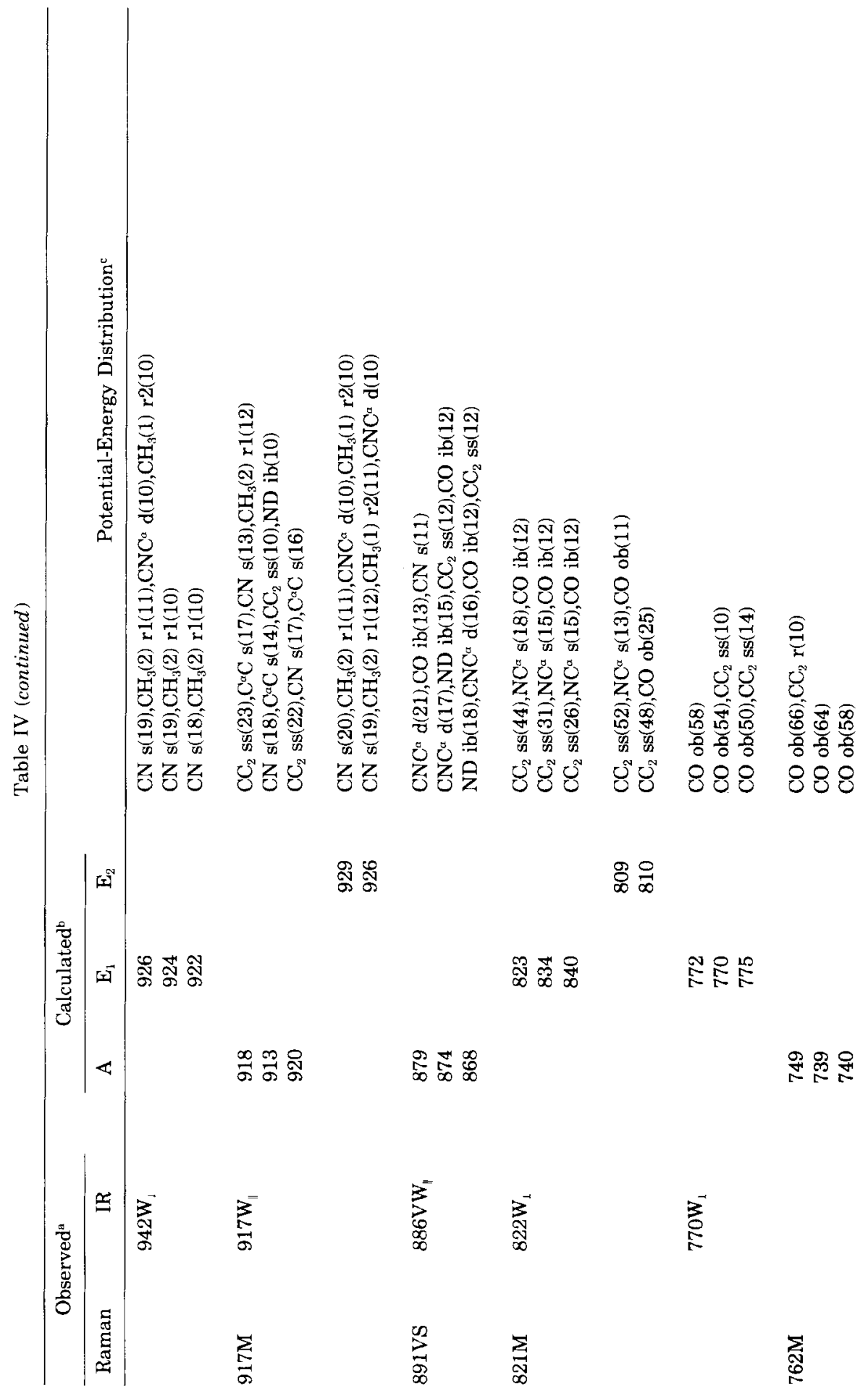


哥矛

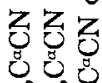

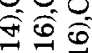

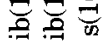

$080 \mathrm{Z}$

สิ่

का के

艺艺

家會

응

88

矛这

3 00 0

ठํํㅇ

홍

只 కొక్ల

क

함

음 80

का

3

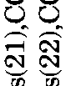

क्ञ

콯

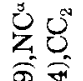

U.

获

$\bar{\square} \Xi$

80

क्षेत

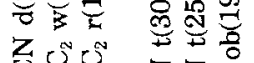

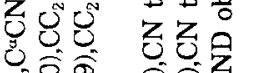

需兽

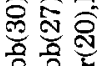

उzz 융융

ठญ

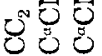

公是导

을을

:

宅

ิㅡㅁ

ㄷํㅇำ

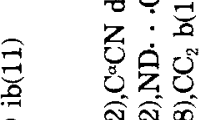

ㅇ ज्ञ

दे

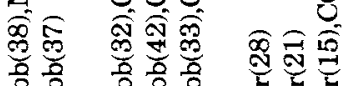

(1)

z $z$ z $z$ o

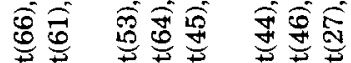

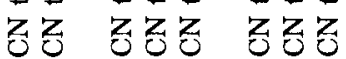

송옹

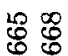

品杽

ชึํํำํำ

总 形昆

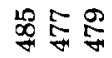

궁ํํ용

串高品

预总学

$\sum_{\substack{i=1 \\ 10}}^{5}$

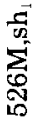

$\underset{\infty}{\sum_{0}^{\circ}}$

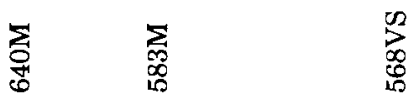




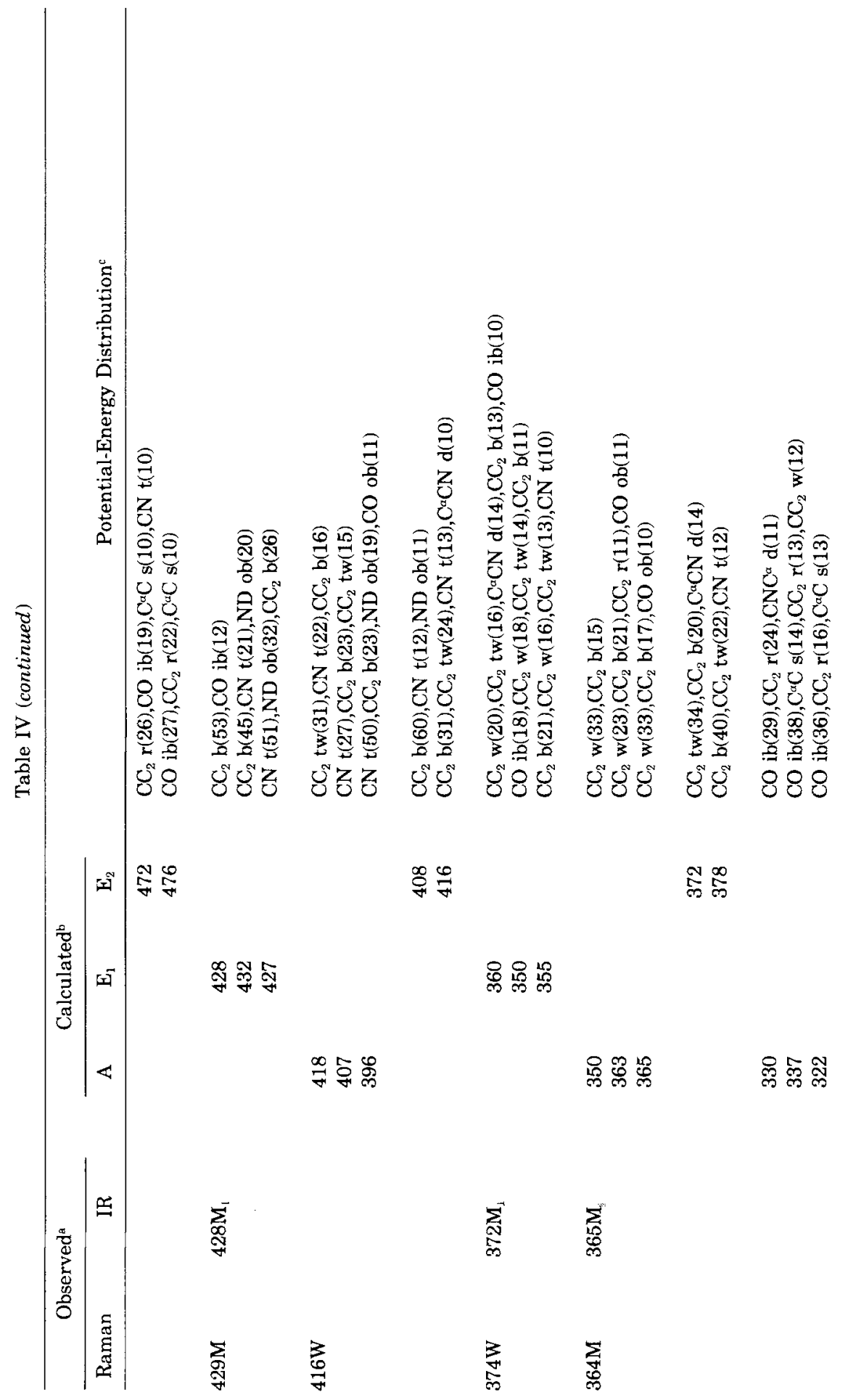


$\stackrel{\widehat{\vartheta}}{\mathrm{t}}$

己ัँ

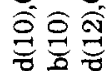

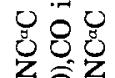

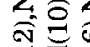

긍

콜

记

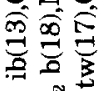

类

88

穿离

क्ले

콩

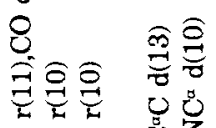

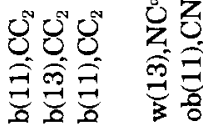

8)

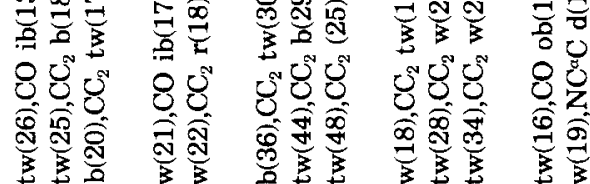

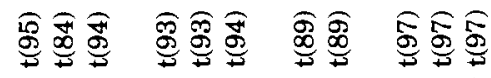

엉요

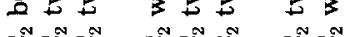

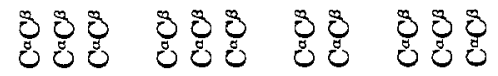

를

:

哭哭

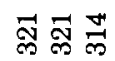

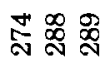

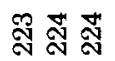

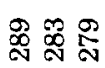

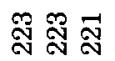

옻옻오

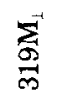

$\sum_{\infty}^{\infty}$

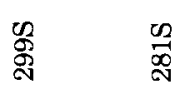

$\sum_{\substack{0 \\ \text { N } \\ \text { a }}}^{3}$

$\underset{10}{3}$ 


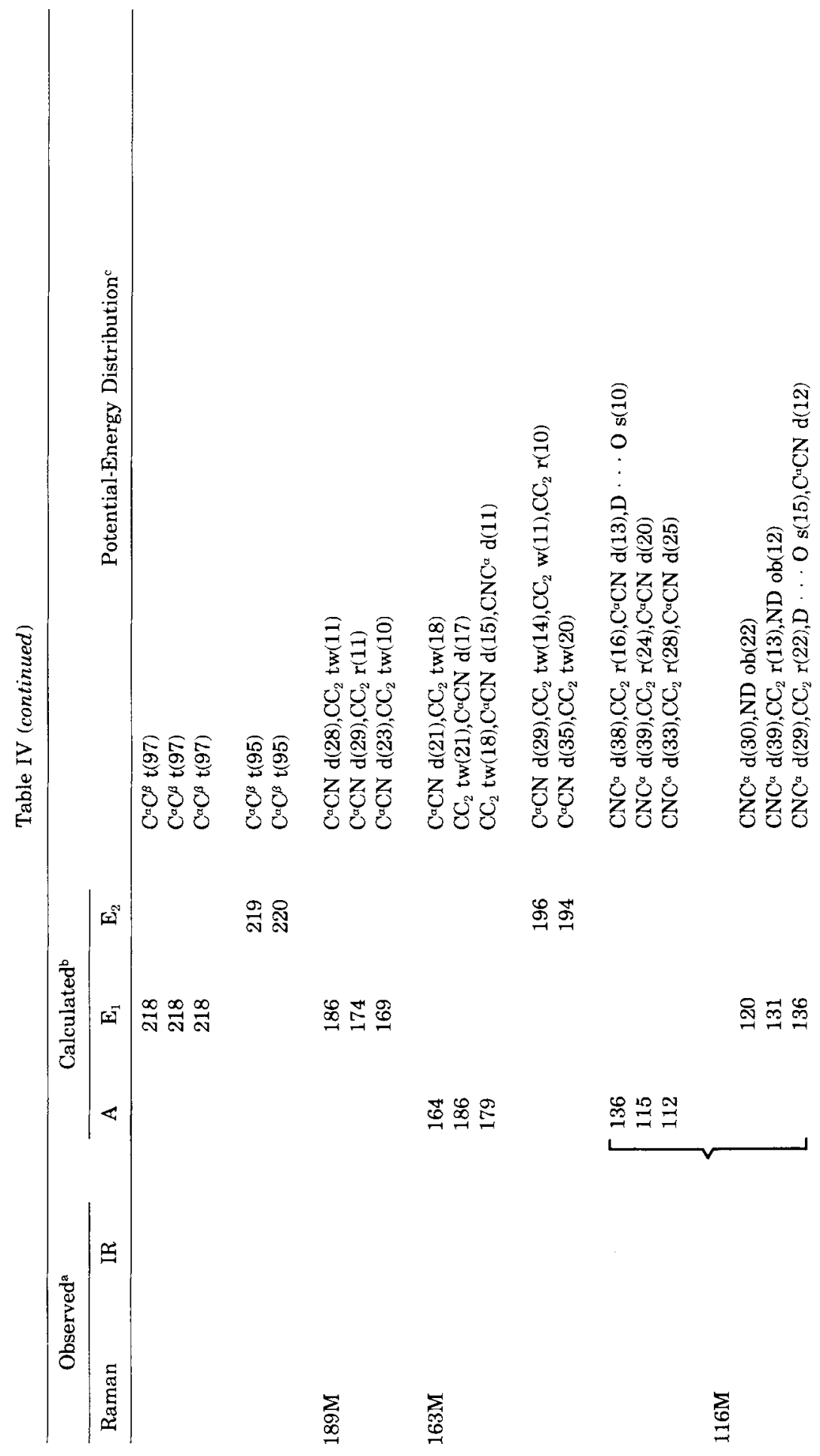




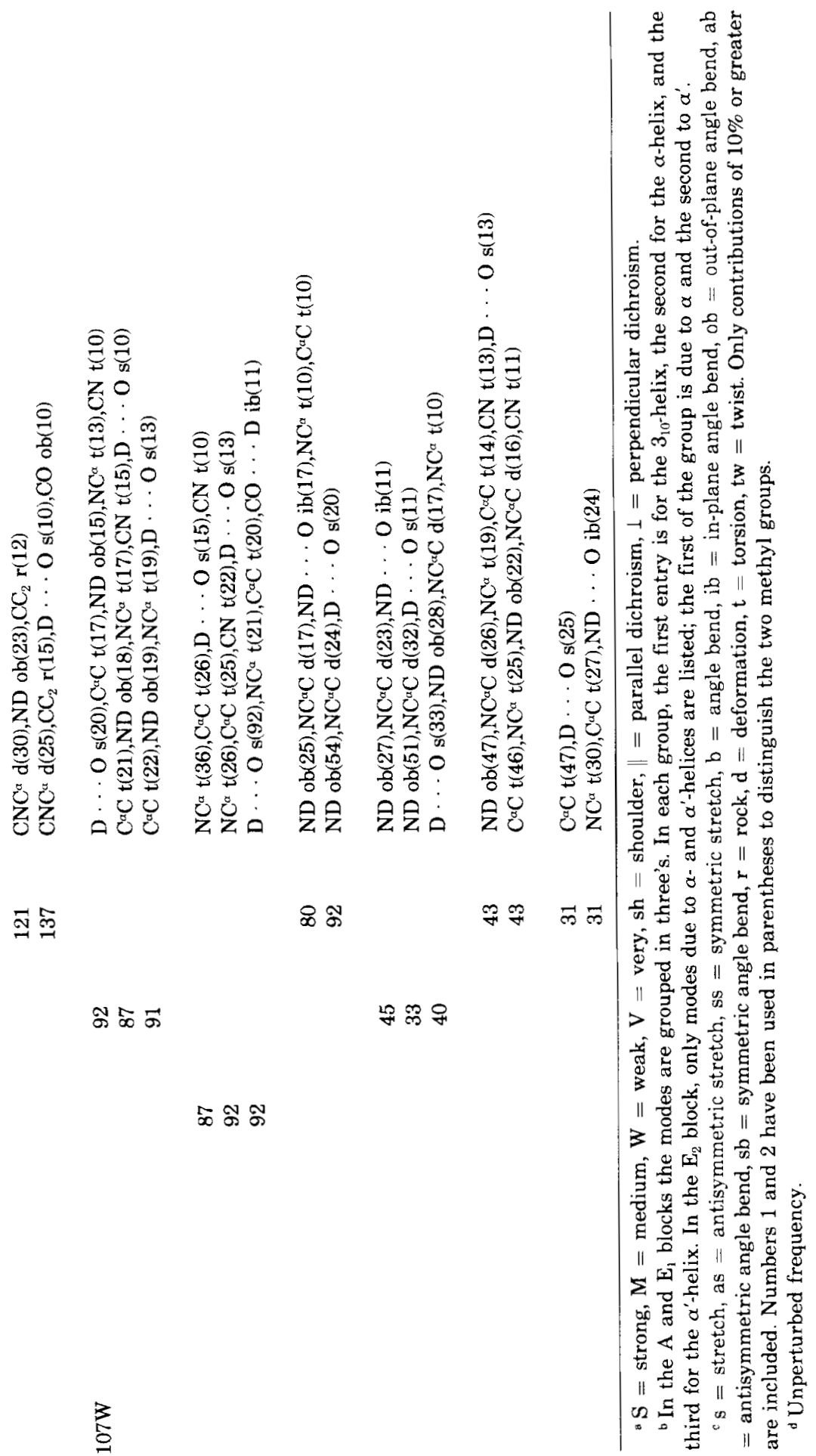


$v_{A}^{0} \cong 3260 \mathrm{~cm}^{-1}$ is now seen to be intermediate between those for $\alpha$ $\left(3279 \mathrm{~cm}^{-1}\right)$ and $\beta$-poly (L-alanine) $\left(3242 \mathrm{~cm}^{-1}\right) .{ }^{34}$ This indicates that the hydrogen bond in PAIB is stronger than that in an $\alpha$-helix, which would be consistent with the proposed $3_{10}$-helix structure (and, incidentally, inconsistent with the $\alpha^{\prime}$-helix structure see Table I). Our adjustment of $f(\mathrm{CO}), f(\mathrm{NH})$, and $f(\mathrm{H} \cdots \mathrm{O}$ ) (see above) is reasonably based on this observation and leads to a good prediction of this frequency. [It is important to note that the predicted frequencies of $v_{A}^{0}$ for the $\alpha$ - and $\alpha^{\prime}$-helices are essentially the same as for the $3_{10}$-helix because we have, inappropriately, kept these force constants the same for all three structures; this was done in order to examine only the effects of conformational differences. Appropriate values of these force constants would result in a higher predicted frequency for the $\alpha$-helix $\left(\sim 3279 \mathrm{~cm}^{-1}\right)$ and a much higher frequency for the $\alpha^{\prime}$-helix.]

The $\nu_{B}^{0}$ values also support a $3_{10}$-helix structure. If, as is likely, ${ }^{34}$ these two bands arise from overtones of amide II, then their observed difference of $27 \mathrm{~cm}^{-1}$ is more consistent with the predicted (and calculated) difference of $28 \mathrm{~cm}^{-1}$ for the $3_{10}$-helix $(2 \times 1545-2 \times 1531$ $=3090-3062=28$ ) than with the expected difference of $42 \mathrm{~cm}^{-1}$ for the other structures. Interestingly, both $v_{B}^{0}$ values are about 20 $\mathrm{cm}^{-1}$ lower than the expected values of the overtones for the $3_{10}$-helix, whereas for $\alpha$-poly(L-alanine), the difference is $4 \mathrm{~cm}^{-1}{ }^{34}$ This may indicate that the anharmonicities in PAIB are significantly different from those in an $\alpha$-helix, thus providing further evidence that the structure is not $\alpha$-helical. Such a difference could arise from the greater crowding of backbone atoms in the $3_{10}$-helix than in the $\alpha$-helix: $\mathrm{C}^{\alpha} \cdots \mathrm{O}, \mathrm{N} \cdots \mathrm{N}$, and $\mathrm{N} \cdots \mathrm{O}$ distances are significantly shorter in the former than in the latter structure.

The $\mathrm{CH}_{3}$ stretch modes are reasonably well accounted for, although we do not reproduce small splittings in the ir bands nor between ir and Raman. As in a similar situation in $\alpha$-poly(L-alanine), ${ }^{18,21}$ such splittings may arise from intermolecular $\mathrm{CH}_{3} \cdots \mathrm{CH}_{3}$ interactions.

The observed difference between Raman and ir amide I (mainly CO stretch) modes is $3 \mathrm{~cm}^{-1}$ in $\alpha$-poly (L-alanine) ${ }^{18}$ and $9 \mathrm{~cm}^{-1}$ in PAIB. The predicted difference for the $3_{10}$-helix is $4 \mathrm{~cm}^{-1}$, but this is twice as large as that predicted for the $\alpha$-helix (with no difference predicted for the $\alpha^{\prime}$-helix). As noted above, these splittings are contributed to by transition dipole coupling interactions and reflect the conformational differences between the helices. The absolute frequency agreement cannot be compared because of the use of the same $f(\mathrm{CO})$ force constant for all three structures. If this force constant were adjusted in accordance with the relative hydrogen-bond strengths, then, as discussed above, a higher frequency would be calculated for the $\alpha$-helix and a much higher frequency for the $\alpha^{\prime}$-helix.

The amide II modes ( $\mathrm{NH}$ in-plane bend plus $\mathrm{CN}$ stretch) are very well predicted by the $3_{10}$-helix, whereas the $\alpha$ - and $\alpha^{\prime}$-helices give sig- 
nificantly lower frequencies than are observed. This must be predominantly a conformational effect, since the relevant force constants are the same for all structures.

The $\mathrm{CH}_{3}$ bend modes are, of course, predicted comparably by all three structures. The frequency agreement is satisfactory, except that the splitting between the $1455_{\perp}$ and $1467_{\|} \mathrm{cm}^{-1}$ bands in the ir is not accounted for by the calculation, probably for reasons similar to those discussed in connection with the $\mathrm{CH}_{3}$ stretch modes.

In the 1350-1200-cm ${ }^{-1}$ region, we find bands associated with $\mathrm{CC}_{2}$ stretch and with amide III (mostly NH in-plane bend) modes. Although the frequency agreement is reasonable for all the structures, the predictions for the $3_{10}$-helix are somewhat better, as is seen for bands near 1303,1280 , and $1212 \mathrm{~cm}^{-1}$. It is gratifying, if not surprising, that the calculation accounts well for strong ir bands at $1227_{\perp}$ and 1210 $\mathrm{cm}^{-1}$ associated with $\mathrm{CC}_{2}$ stretch, in a region where no absorption is found for $\alpha$-poly(L-alanine). ${ }^{18,21}$

In the $1200-700-\mathrm{cm}^{-1}$ region, most modes allow no real distinction to be made between the three structures. (We have no explanation for the Raman bands observed in the $1125-1040-\mathrm{cm}^{-1}$ region: none of the structures predicts such vibrational modes. The intensity level in this region varies from sample to sample and seems to be related to the fluorescence of the sample.) The observed bands near $820 \mathrm{M} \mathrm{cm}^{-1}$ distinctly favor the $3_{10}$-helix (although this is countered by the poorer agreement for the $762 \mathrm{~W}$ Raman band).

In the conformation-sensitive region below $700 \mathrm{~cm}^{-1}$, several observed bands strongly favor the $3_{10}$-helix. Thus, the amide $\mathrm{V}$ (NH outof-plane bend plus $\mathrm{CN}$ torsion) modes at $694 \mathrm{~S}_{1}$ and $680 \mathrm{M}_{1} \mathrm{~cm}^{-1}$ in the ir are very well accounted for by the $3_{10}$-helix, but very large discrepancies occur for the $\alpha$ - and $\alpha^{\prime}$-helices. A Raman band at $642 \mathrm{~W} \mathrm{~cm}^{-1}$ is satisfactorily predicted by the $3_{10}$-helix structure but not as well by the others. The observed bands near $425 \mathrm{~cm}^{-1}$ are best accounted for by the $3_{10}$-helix. And the correct order of the $367 \mathrm{M}_{\perp}$ and $362 \mathrm{~S}_{\|} \mathrm{CC}_{2}$ wag modes is given only by the $3_{10}$-helix.

In summary, several key features in the comparison between observed and calculated frequencies of PAIB definitively favor a predominant $3_{10}$-helix conformation of this polypeptide in monolayer films. The $\alpha^{\prime}$-helix is clearly disfavored.

\section{Poly( $\alpha$-Aminoisobutyric Acid)-ND}

The results of $\mathrm{N}$-deuteration are consistent with the normal mode calculation on PAIB. They also favor, although not as conclusively, the $3_{10}$-helix.

The ND stretch modes are found at $2414 \mathrm{~S}$ and $2460 \mathrm{M} \mathrm{cm}^{-1}$ in the ir. In distinction to $\alpha$-poly(L-alanine), ${ }^{34}$ the fundamental contributes mostly to the lower frequency. Also, no splitting is observed in amide 
B', which was the case for PAIB. From the observed integrated area ratio $I_{\mathrm{B}^{\prime}} / I_{\mathrm{A}^{\prime}}=0.794$, we find $\nu_{\mathrm{A}^{\prime}}^{0}=2434$ and $\nu_{\mathrm{B}^{\prime}}^{0}=2440 \mathrm{~cm}^{-1}$. The calculated ND stretch frequency, using the same value of $f(\mathrm{NH})$ as in PAIB, is $37 \mathrm{~cm}^{-1}$ lower than $\nu_{\mathrm{A}^{\prime}}^{0}$. This is similar to the situation for $\alpha$ and $\beta$-poly(L-alanine-ND), ${ }^{34}$ where differences of $40-50-\mathrm{cm}^{-1}$ occur, and is probably due to different anharmonicities in PAIB and PAIB-ND. If $v_{\mathrm{B}^{\prime}}^{0}$ is associated with a combination similar to that found in poly $(\mathrm{L}-$ alanine-ND), ${ }^{34}$ namely, between amide $\mathrm{II}^{\prime}$ (mainly $\mathrm{CN}$ plus $\mathrm{C}^{a} \mathrm{C}$ stretch) and ND in-plane bend, then a possibility is $1472\left(\mathrm{E}_{1}\right)+966\left(\mathrm{E}_{1}\right)=$ 2438(A). The specific combination may be uncertain because of lack of information about anharmonicities.

The CO stretch mode is found to shift down by $16 \mathrm{~cm}^{-1}$ in the ir, from 1656 to $1640 \mathrm{~cm}^{-1}$, significantly more than the $8 \mathrm{~cm}^{-1}$ observed in $\alpha$-poly(L-alanine). ${ }^{18,21}$ (We attribute the observed ir bands near 1655 and $1650 \mathrm{~cm}^{-1}$ to the presence of a significant amount of undeuterated material.) The calculated decreases are 10,8 , and $7 \mathrm{~cm}^{-1}$ for the $3_{10^{-}}$, $\alpha$-, and $\alpha^{\prime}$-helices, respectively. The comparable Raman shift is $7 \mathrm{~cm}^{-1}$ compared to $3 \mathrm{~cm}^{-1}$ for $\alpha$-poly(L-alanine). The calculated shift in this case is $6 \mathrm{~cm}^{-1}$, the same for all three structures.

The appearance of the amide II' mode at $1472 \mathrm{~cm}^{-1}$ is expected and reasonably well predicted. The $\mathrm{CH}_{3}$ antisymmetric bend modes of PAIB near 1467(ir) and $1450(\mathrm{R}) \mathrm{cm}^{-1}$ are also observed in PAIB-ND, but what is surprising is that other $\mathrm{CH}_{3}$ bend modes appear in the spectra of the deuterated molecule. This would seem to be the case for the surprisingly strong new band at $1424 \mathrm{~cm}^{-1}$ (which is not too well predicted) and a $\mathrm{CH}_{3}$ symmetric bend mode near $1375 \mathrm{~cm}^{-1}$. Assuming these assignments to be correct, such intensity changes may arise from a change in the local environment of the $\mathrm{CH}_{3}$ groups.

The observed bands in PAIB having a significant $\mathrm{NH}$ in-plane bend component, viz., at $1339(\mathrm{R}), 1313(\mathrm{R})$, and $1280(\mathrm{R}, \mathrm{ir}) \mathrm{cm}^{-1}$, disappear, as expected, on $\mathrm{N}$-deuteration, which is well accounted for by the calculation on PAIB-ND. As a result, although some of the other modes in this general region $\left(1350-1150 \mathrm{~cm}^{-1}\right)$ are predicted to remain essentially constant, and do (e.g., near 1230 and $1210 \mathrm{~cm}^{-1}$ ), still others are expected to shift: the mode near $1300 \mathrm{~cm}^{-1}$ is predicted to shift up slightly, but is found to move about the same amount in the opposite direction; and the mode near $1170 \mathrm{~cm}^{-1}$ is predicted to shift up significantly and change in character, and the observed band in PAIB is absent in the spectra of PAIB-ND. It is difficult to choose between the structures on the basis of this region, although the small shift in the 1210 (ir) $\mathrm{cm}^{-1}$ band and the frequency agreement for the $1229(\mathrm{R}) \mathrm{cm}^{-1}$ band would both tend to favor the $3_{10}$-helix. Incidentally, the new bands in PAIB-ND near 1010 and $980 \mathrm{~cm}^{-1}$ due to ND in-plane bend are moderately well accounted for by the calculation, although they can provide no diagnostic help because of the uncertainties about anharmonicities. 
In the $1000-500-\mathrm{cm}^{-1}$ region, the skeletal stretch and deformation modes behave generally as predicted, with a tendency to favor the $3_{10^{-}}$ helix. The $950(\mathrm{R}) \mathrm{cm}^{-1}$ band of PAIB is predicted to shift down by about $5 \mathrm{~cm}^{-1}$, and is observed to do so. The predicted downward shift of the PAIB bands near $920 \mathrm{~cm}^{-1}$ is found, although a structural preference is not possible. The case of the $908(\mathrm{R}) \mathrm{cm}^{-1}$ band of PAIB is an interesting one. It is predicted to undergo a large shift in PAIBND, which is found, with this shift being in slightly better agreement with the $3_{10}$-helix than the $\alpha$-helix and in very poor agreement with the predictions of the $\alpha^{\prime}$-helix. As in PAIB, the bands near $820 \mathrm{~cm}^{-1}$ clearly favor the $3_{10}$-helix, as is now true of the $762(\mathrm{R}) \mathrm{cm}^{-1}$ band and continues to be the case for the $640(\mathrm{R}) \mathrm{cm}^{-1}$ band. The $583(\mathrm{R}) \mathrm{cm}^{-1}$ band of PAIB is poorly reproduced by the $3_{10}$-helix, but this may be due to the contribution of ND out-of-plane bend. A similar problem may exist with the $526(\mathrm{ir}) \mathrm{cm}^{-1}$ band. The calculation suggests that the character and frequency of the 505 (ir) $\mathrm{cm}^{-1}$ band of PAIB should change significantly in PAIB-ND, but this is not apparent, and it is therefore difficult to use this band as an indicator of structure.

Below $500 \mathrm{~cm}^{-1}, \mathrm{~N}$-deuteration does not produce many changes in PAIB-ND as compared to PAIB. It is interesting, however, that a calculated A-species mode near $430 \mathrm{~cm}^{-1}$ in PAIB, for which there was no observed counterpart, is predicted to shift down significantly in PAIB-ND, and the new observed $416(\mathrm{R}) \mathrm{cm}^{-1}$ band is in distinctly better agreement with the $3_{10}$-helix.

\section{CONCLUSIONS}

The ir and Raman spectra of PAIB prepared as monomolecular films, when combined with normal mode calculations on $3_{10}, \alpha$-, and $\alpha^{\prime}$-helices, indicate strongly that the chain backbone has a $3_{10}$-helix conformation. This is in agreement with conclusions reached from electron diffraction studies. ${ }^{7.8}$

It is not only that the average discrepancy between observed and calculated frequencies is significantly less for the $3_{10}$-helix as compared to the other two helical structures, although this is the case: for observed bands below $1700 \mathrm{~cm}^{-1}$ the average observed discrepancy is 5.9 $\mathrm{cm}^{-1}$ for the $3_{10^{-}}$-helix, $10.1 \mathrm{~cm}^{-1}$ for the $\alpha$-helix, and $12.5 \mathrm{~cm}^{-1}$ for the $\alpha^{\prime}$-helix. (We note that a discrepancy of $5-6 \mathrm{~cm}^{-1}$ is typical of that found for the standard $\alpha$-helix and $\beta$-sheet structures to which the force field was refined. ${ }^{23}$ ) More importantly, certain special features of the spectra are accounted for better by the $3_{10}$-helix: the presence and observed splitting of the two $\nu_{B}^{0}$ modes, where only one band is seen for the $\alpha$-helix; the larger splitting between ir and Raman amide I modes than is predicted, or found, for $\alpha$-helix structures; the significantly higher amide II frequency; and the significantly better agreement for the amide $\mathrm{V}$ mode. Other, more general, agreement with the $3_{10}$-helix is evident throughout the spectral range. 
These results demonstrate the power of normal mode analysis in permitting critical distinctions in conformation to be made from vibrational spectra.

We thank Dr. V. Sasisekharan for providing the coordinates of the $3_{10}$-helix structure. This research was supported by NSF Grants PCM-8214064 and DMR-8303610.

\section{References}

1. Burgess, A. W. \& Leach, S. J. (1973) Biopolymers 12, 2599-2605.

2. Venkataram Prasad, B. V. \& Sasisekharan, V. (1979) Macromolecules 12, 11071110.

3. Paterson, Y., Rumsey, S. M., Benedetti, E., Némethy, G. \& Scheraga, H. A. (1981) J. Am. Chem. Soc. 103, 2947-2948.

4. Paterson, Y., Stimson, E. R., Evans, D. J., Leach, S. J. \& Scheraga, H. A. (1982) Int. J. Pept. Protein Res. 20, 468-480.

5. Benedetti, E., Bavoso, A., DiBlasio, B., Pavone, V., Pedone, C., Toniolo, C. \& Bonora, G. M. (1982) Proc. Natl. Acad. Sci. USA 79, 7951-7954.

6. Marshall, G. R. \& Bosshard, H. E. (1972) Circ. Res. Suppl. II 30/31, 143-150.

7. Malcolm, B. R. (1977) Biopolymers 16, 2591-2592.

8. Malcolm, B. R. (1983) Biopolymers 22, 319-321.

9. Shamala, N., Nagaraj, R. \& Balaram, P. (1977) Biochem. Biophys. Res. Commun. 79, 292-298.

10. Smith, G. D., Duax, W. L., Czerwinski, E. W., Kendrick, N. E., Marshall, G. R. \& Matthews, F. S. (1977) Peptides: Proceedings of the Fifth American Peptide Symposium, Wiley, New York, pp. 277-279.

11. Shamala, N., Nagaraj, R. \& Balaram, P. (1978) J. Chem. Soc. Commun., 996-997.

12. Venkataram Prasad, B. V., Shamala, N., Nagaraj, R. \& Balaram, P. (1980) Acta Crystallogr., Sect. B 36, 107-110.

13. Nagaraj, R., Shamala, N. \& Balaram, P. (1979) J. Am. Chem. Soc. 101, 16-20.

14. Venkataram Prasad, B. V., Shamala, N., Nagaraj, R., Chandrasekaran, R. \& Balaram, P. (1979) Biopolymers 18, 1635-1646.

15. Smith, G. D., Pletnev, V. Z., Duax, W. L., Balasubramanian, T. M., Bosshard, H. E., Czerwinski, E. W., Kendrick, N. E., Matthews, F. S. \& Marshall, G. R. (1981) J. Am. Chem. Soc. 103, 1493-1501.

16. Moore, W. H. \& Krimm, S. (1976) Biopolymers 15, 2439-2464.

17. Moore, W. H. \& Krimm, S. (1976) Biopolymers 15, 2465-2483.

18. Rabolt, J. F., Moore, W. H. \& Krimm, S. (1977) Macromolecules 10, 1066-1074.

19. Dwivedi, A. M. \& Krimm, S. (1982) Macromolecules 15, 177-185.

20. Dwivedi, A. M. \& Krimm, S. (1982) Macromolecules 15, 186-193; (1983) 16, 340.

21. Dwivedi, A. M. \& Krimm, S. (1984) Biopolymers 23, 923-943.

22. Dwivedi, A. M. \& Krimm, S. (1984) J. Phys. Chem. 88,620-627.

23. Krimm, S. (1983) Biopolymers 22, 217-225.

24. Bandekar, J. \& Krimm, S. (1979) Prac. Natl. Acad. Sci. USA 76, 774-777.

25. Krimm, S. \& Bandekar, J. (1980) Biopolymers 19, 1-29.

26. Bandekar, J. \& Krimm, S. (1980) Biopolymers 19, 31-36.

27. Maxfield, F. R., Bandekar, J., Krimm, S., Evans, D. J., Leach, S. J., Némethy, G. \& Scheraga, H. A. (1981) Macromolecules 14, 997-1003.

28. Bandekar, J., Evans, D. J., Krimm, S., Leach, S. J., Lee, S., McQuie, J. R., Minasian, E., Némethy, G., Pottle, M. S., Scheraga, H. A., Stimson, E. R. \& Woody, R. W. (1982) Int. J. Pept. Protein Res. 19, 187-205.

29. Krimm, S. \& Dwivedi, A. M. (1982) Science 216, 407-408.

30. Dwivedi, A. M. \& Krimm, S. (1982) Biopolymers 21, 2377-2397.

31. Elliott, A. (1954) Proc. R. Soc. London, Ser. A 226, $408-421$. 
32. Arnott, S. \& Dover, S. D. (1967) J. Mol. Biol. 30, 209-212.

33. Donohue, J. (1953) Proc. Natl. Acad. Sci. USA 39, 470-478.

34. Krimm, S. \& Dwivedi, A. M. (1982) J. Raman Spectrosc. 12, 133-137.

Received December 12, 1983

Accepted April 9, 1984 